Influência de uma intervenção pedagógica orientada para tarefa, na percepção de competência física e na execução de habilidades específicas do Ballet Clássico: um estudo com crianças de quatro e cinco anos de idade.

Carolina Komiyama 
Influência de uma intervenção pedagógica orientada para tarefa, na percepção de competência física e na execução de habilidades específicas do Ballet Clássico: um estudo com crianças de quatro e cinco anos de idade.

Carolina Komiyama

Dissertação/Tese apresentada à Escola de Educação Física e Esporte da Universidade de São Paulo, como requisito parcial para obtenção do grau de Mestre/Doutor em Educação Física. 
Komiyama, Carolina

Influência de uma intervenção pedagógica orientada para tarefa, na percepção de competência física e na execução de habilidades específicas do Ballet Clássico: um estudo com crianças de quatro e cinco anos de idade / Carolina Komiyama. - São Paulo: [s.n.]. 2008.

Ix, 64p.

Dissertação (Mestrado) - Escola de educação Física e Esporte da Universidade de São Paulo.

Orientador: Prof. Dr. Osvaldo Luiz Ferraz

1.Percepção de Competência Física 2. Ballet Clássico 3. Educação infantil I. Título. 


\section{AGRADECIMENTOS}

Agradeço, primeiramente, a Deus por me orientar nos momentos mais difíceis e não permitir que eu desistisse!

À minha amada mãe, para a qual não tenho palavras que possam representar tamanha gratidão. Gratidão pela companhia de horas a fio, nas digitações, nas pesquisas e nos abraços, entre as paradas de cansaço! Gratidão pela presença, nas muitas apresentações, dando uma força celestial para minhas danças! Gratidão pelo amor incondicional, que não mede sequer um gesto para me deixar feliz!

Ao meu querido orientador, que passou por momentos tão delicados de vida e mesmo assim pôde, na medida certa, ensinar-me o que era necessário para uma tarefa bastante árdua. Que soube entender também as intempéries que a vida causou em minha existência, e esteve do meu lado, até o último minuto.

Ao meu amor e companheiro que acompanhou, de perto, todo meu esforço e dedicação.

À minha amada filha, que entre leituras e digitações, entre traduções e idéias, esteve sempre presente motivando-me com um beijo, com uma gracinha, com um choro, a me tornar alguém com mais conhecimentos, buscando melhores horizontes na vida.

A todas as pessoas que se dispuseram a me ajudar, para que eu pudesse continuar investindo no que eu acredito ser minha missão de vida. 
SUMÁRIO

Página

LISTA DE TABELAS......................................................... iv

LISTA DE FIGURAS........................................................... $\mathrm{v}$

RESUMO_........................................................................... vi

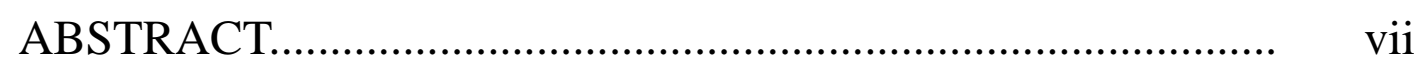

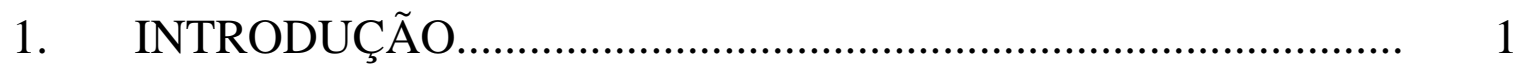

2. JUSTIFICATIVA.................................................................... 11

3. OBJETIVO................................................................... 12

4. REVISÃO BIBLIOGRÁFICA.................................................... 12

4.1. Ballet Clássico e Educação Física..................................................... 12

4.2. Ballet Clássico, auto-estima e autoconceito.................................... 13

4.3. Percepção de Competência........................................................... 16

4.4. Percepção de Competência e diferentes tipos de intervenção

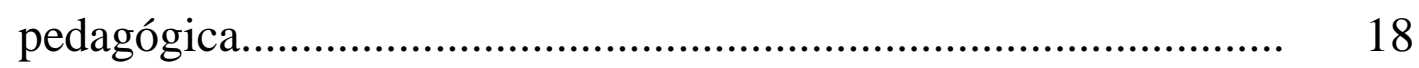

4.5. O instrumento de avaliação TARGET............................................ 37

5. METODOLOGIA................................................................... 41

5.1. Estudo 1: Percepção de Competência.............................................. 42

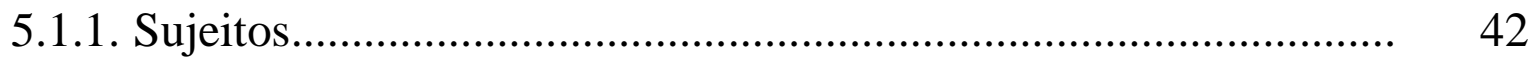

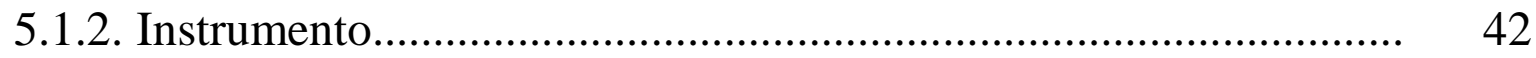

5.1.3. Procedimento de coleta de dados.................................................... 46

5.1.4. Procedimento de análise dos dados................................................. 47 


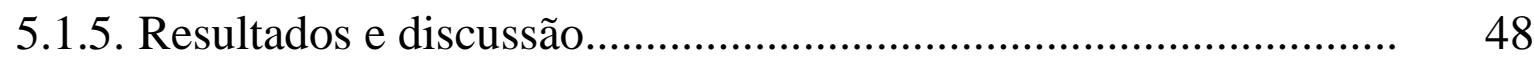

5.2. Estudo 2: Habilidades específicas do Ballet Clássico..................... 50

5.2.1. Sujeitos.............................................................................. 50

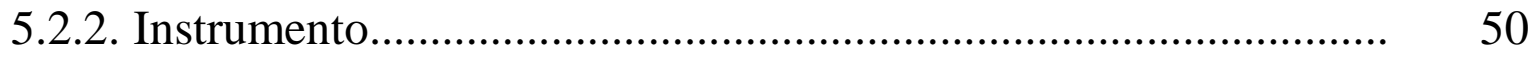

5.2.3. Procedimento de coleta de dados................................................... 54

5.2.4. Procedimento de análise dos dados................................................ 54

5.2.5. Resultados e discussão.................................................................. 55

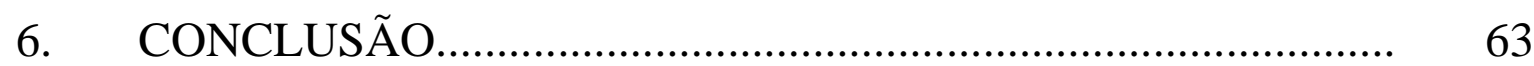

7. REFERÊNCIAS BIBLIOGRÁFICAS........................................... 65

8. ANEXO I - The pictorial scale of perceived competence and acceptance for young children..................................................... 73

8.1. ANEXO II - Registro individual e folha de pontuação................... 74

9. APÊNDICE 1 - Pontuação do teste de habilidades específicas para crianças de quatro anos........................................................ 75

9.1. APÊNDICE 2 - Pontuação do teste de habilidades específicas para crianças de cinco anos........................................................... 77

9.2. APÊNDICE 3 - Pontuação do teste de percepção de competência física para crianças de quatro anos................................................. $\quad 79$

9.3. APÊNDICE 4 - Pontuação do teste de percepção de competência física para crianças de cinco anos...................................................

9.4. APÊNDICE 5 - Pontuação individual dos avaliadores na execução das habilidades específicas para o grupo de quatro anos e de cinco anos 


\section{LISTA DE TABELAS}

Página

TABELA 1 - Estatística das variáveis "competência física" nos grupos de 4 e 5 anos................................... 49

TABELA 2 - $\quad$ Estatística das variáveis "habilidades específicas" nos grupos de 4 e 5 anos............... 53

TABELA 3 - Estatística das variáveis "habilidades" nos grupos de 4 e 5 anos.................................. 56 


\section{LISTA DE FIGURAS}

Página

FIGURA 1 - Mecanismos cognitivos e afetivos e tipo de intervenção pedagógica.................................... 20

FIGURA 2 - $\quad$ Descrições do TARGET e estratégias de aula... 40

FIGURA 3 - Média de percepção de competência "pré" e "pós" programa................................................... 48

FIGURA 4 - $\quad$ Média da execução de habilidades específicas. 56

FIGURA 5 - Média da execução das habilidades específicas "pré" e "pós" programa para crianças de 5 anos

FIGURA 6 - Média da execução das habilidades específicas "pré" e "pós" programa para crianças de 4 anos 
RESUMO

\title{
INFLUÊNCIA DE UMA INTERVENÇÃO PEDAGÓGICA ORIENTADA PARA TAREFA, NA PERCEPÇÃO DE COMPETÊNCIA FÍSICA E NA EXECUÇÃO DE HABILIDADES ESPECÍFICAS DO BALLET CLÁSSICO: UM ESTUDO COM CRIANÇAS DE QUATRO E CINCO ANOS DE IDADE
}

\author{
Autor: Carolina Komiyama \\ Orientador: Prof. Dr. Osvaldo Luiz Ferraz
}

O Ballet Clássico é muito oferecido como atividade extracurricular em escolas de educação infantil. Os tipos de intervenções pedagógicas que permeiam o ensino dessa atividade estão voltados, na maioria das vezes, para o desempenho de suas habilidades específicas. No entanto, muitos estudos com diferentes modalidades esportivas vêm sendo desenvolvidos com o objetivo de verificar os tipos de intervenções pedagógicas existentes para o ensino e aprendizagem das mesmas. Os resultados mostram que dois tipos divergentes são possíveis: um tipo de intervenção pedagógica voltado para a tarefa e outro voltado para o desempenho. Além disso, muitas pesquisas estão estudando a relação desses diferentes tipos de intervenção nas dimensões físicas, cognitivas, sociais e emocionais dos indivíduos. Um aspecto bastante estudado é a relação do tipo de intervenção com a percepção de competência. O objetivo desse estudo foi verificar, após um programa de aulas de Ballet Clássico com um tipo de intervenção pedagógica voltada para a tarefa, a execução de habilidades específicas pré-determinadas do Ballet e o nível de percepção de competência física, em crianças de quatro (4) e cinco (5) anos. Os resultados encontrados mostraram que no final do programa a maioria das crianças alcançou um nível avançado na execução das habilidades específicas e que todos os 
participantes aumentaram sua percepção de competência física. Sendo assim, pode-se

concluir que as intervenções pedagógicas voltadas para a tarefa, mostram-se como uma maneira eficiente no ensino do Ballet Clássico para crianças; além de aprenderem suas habilidades específicas, vivenciam experiências de sucesso, adaptadas a seus níveis de desenvolvimento físico, cognitivo e afetivo-social. São necessários mais estudos sobre os benefícios desse tipo de intervenção para crianças dentro da faixa etária proposta, nas diferentes atividades das quais participam. Contribuir, de forma positiva, no crescimento e desenvolvimento das crianças, em suas diferentes dimensões, não é uma tarefa fácil, porém deve ser considerada fundamental, uma vez que nós, educadores, somos co-responsáveis pela formação da nossa futura sociedade.

Palavras-chave: Percepção de Competência - Ballet Clássico - Educação Infantil 
ABSTRACT

INFLUENCE OF AN EDUCATIONAL TASK ORIENTED PROGRAM IN THE PERCEIVED PHYSICAL COMPETENCE AND IN THE PERFORMANCE OF MOTOR SKILLS CLASSICAL BALLET: A STUDY WITH CHILDREN WITH FOUR AND FIVE YEARS OLD

\author{
Author: Carolina Komiyama \\ Adviser: Prof. Dr. Osvaldo Luiz Ferraz
}

The Classical Ballet is offen offered as extracurricular activities at kindergarten. The types of pedagogic interventions permeating the teaching of this activity is focused on the performance of their specific skills. However, many studies with differents sports modalities are being developed with the objective of verifying the types of interventions in the learning of their skills. The results show that two divergents types are possible: a type of educational intervention oriented to the task and another oriented to the performance. Moreover, many researches are studying the relationship of these different types of intervention on the individuals physical, cognitive, social and emotional dimentions. One well studied topic is the relationship of the type of intervention with the perceived competence. The aim of this study was describe, after a classical ballet program oriented to the task, the performance of predetermined ballet skills and the level of physical perception competence in children with four and five years old. The results of this study showed that at the end of the program, most of the children reached an advanced level in the performance of the specific skills and that all participants increased their perception of physical competence. Therefore we can conclude that the interventions oriented to the task, showed to be an efficient manner in classical ballet teaching for children; in besides 
learning their specialized skills, children experiences succes adapted to their level of physical, cognitive and affective-socail development. Future research should examine

the benefits of this type of intervention for children in the age group proposal in the various activities in wich thus participate. It is not easy to contribute in a positive way, to the children growth and development in its various dimensions, but it should be considered essential, since we, educators are coresponsible for the development of our future society.

Key words: Perceived Competence - Classical Ballet - Kindergarten 


\section{Introdução}

Arte secular originária de uma cultura basicamente francesa em meados do século XV, o Ballet Clássico permanece, até hoje, entre as mais belas e extraordinárias expressões de sentimentos, por meio de movimentos sutis e delicados, ao mesmo tempo rápidos e precisos, envolvidos em composições musicais eruditas.

Sua complexidade apresenta-se na maneira como os bailarinos desenvolvem seus passos e dançam suas coreografias. A combinação perfeita entre braços e pernas, juntamente com o tempo musical, tornam-na tão exigente que o mais habilidoso dos bailarinos necessita de horas de treinamento para atingir a perfeição. $\mathrm{O}$ resultado são movimentos altamente refinados, dançados com suavidade, envolvidos em roupas e cenários suntuosos, revelando a grandiosidade da cultura francesa de onde fora originado e, aos poucos, aprimorado também pelas culturas italiana e russa.

Esta excelência iniciou-se por volta do século XII, na França, com as danças metrificadas, também chamadas de dança de corte, sendo aprimorada no Quattrocento e Cinquecento italiano, por uma técnica mais exigente, onde era necessário saber a métrica e os passos criados por professores de dança, que faziam parte do meio imediato dos príncipes.

O Ballet de Corte, originado na França, em meados do século XVI, representa, primeiramente, um meio privilegiado de propaganda e afirmação do poder real como único modo de paz e prosperidade. Depois que a autoridade real foi solidificada, o ballet transformou-se de afirmação do princípio monárquico, em cerimônia de adulação da pessoa do rei.

Sua técnica mais sofisticada tinha as danças de corte à sua disposição, por isso, pode ser caracterizado por um baile organizado em torno de uma ação dramática, que poderia ser o casamento de um príncipe, a visita de um amigo do rei, batalhas vencidas, entre outros.

O Ballet de Corte introduz os desenhos geométricos de solo, que utiliza as 
diferentes formas como círculo, quadrados, losangos e retângulos, para dar movimento e vivacidade às suas danças. Além disso, o Ballet de Corte apresenta outro elemento novo que são as chamadas entrées ou árias, caracterizadas como entradas de dança livre, geralmente improvisadas, reservadas a temas específicos, tais como: combates e festas de corte. Os profissionais envolvidos nas criações destes ballets e os profissionais que participavam como bailarinos eram cortesãos, amigos da classe alta. Neste período, entre a classe menos favorecida, surgiram os bailarinos profissionais que, aos poucos, tomaram o lugar dos bailarinos cortesãos e dos amadores.

Entre a França de Luís XIII para a de Luís XIV o Ballet de Corte ficou estagnado nas antigas criações. Com a soberania do novo rei, a sociedade francesa de corte é aprisionada num modo de vida rígido e as artes numa contemplação intensa pela mitologia, e, portanto, pela Antigüidade, concebida não como o conhecimento de um sistema próprio de cultura, mas como uma garantia de eternidade à cultura do tempo. Desta forma as artes surgem artificial e rigorosas, onde o significante tem mais importância que o significado e o gesto mais importância que a emoção que o produz.

A Dança Clássica surge nesta época, com Charles-Louis-Pierre de Beauchamps que, como todos os artistas oficiais da época, quis impor à dança uma organização reconhecida universalmente. Sendo assim, sua dança tendeu à beleza das formas e à rigidez. Beauchamps trabalhou a partir dos passos de dança de corte atribuindo-lhes beleza formal, uma regra dentro da qual se fixava a via de sua evolução, ou seja, tratava-se de tomar um movimento natural, levá-lo ao máximo de seu desenvolvimento, tornando-o, assim, forçosamente artificial.

A escola clássica inicia-se no século XVIII, em meio a uma monarquia absoluta na teoria e extremamente questionada na prática. No campo econômico, a França é o país maior e mais rico. No plano social, há a ascensão de uma classe burguesa rica que assume o poder da sociedade. No plano ideológico, a cidade é o centro das novas idéias, de abordagens liberadas da opressão da autoridade. A cultura 
passa a ter um público maior: magistrados, pequenos burgueses, baixo clero e camponeses. A igreja perde seu grande prestígio e influência. Por fim, as artes, incluindo a dança, mostram que o princípio do século é ser feliz.

A dança nesse período, embora estivesse imbuída pelas grandes mudanças, apresentou-se formal por quase metade do século. Foi somente com Noverre, que ela tomou um caminho um pouco mais voltado ao realismo de temas e técnicas rumo à expressão da sensibilidade.

Raoul-Auger Feuillet e Pierre Rameuau, coreógrafos e mestres, criam, de acordo com as inovações de Beauchamps, mais de quatrocentos e sessenta passos. A dança passa a ter uma linha definida: são codificados os passos e o sentido corporal. Desta forma, o ensinamento torna-se mais fácil, uniformiza-se e ganha vigor, permitindo o desabrochar do virtuosismo.

Foi nesta grande exigência, na busca da perfeição, na repetição de cenas, atos, passos e contra o ballet formal, que, por volta de 1754, iniciou-se, com Luís de Cahusac, um movimento de contestação por meio de sua obra intitulada Danse ancienne et moderne ou traité historique de La danse. Nesta obra, o autor critica a forma como o ballet é desenvolvido:

“... a opinião pública diz que a dança deve se reduzir a um desenvolvimento de belas proporções do corpo, a uma grande precisão na execução das árias, à graça no porte dos braços, a uma extrema leveza na formação dos passos..."

(Cahusac, L., citado por Boucier, P., 2006, p.

$\mathrm{O}$ autor combate também o peso da hierarquia do ballet e os privilégios dos primeiros bailarinos

“... se há oito bailarinos ou bailarinas na ópera, que têm o direito de ter, cada um duas entrées particulares, é preciso imaginar dezesseis entrées, ações separadas que se liguem ou tenham relação com a ação principal, e ainda supor que esses oito indivíduos consentirão em executá-las. Essas 
duas condições são moralmente impossíveis..."

(Cahusac, L., citado por Boucier, P., 2006, p.

Em seguida, com uma doutrina melhor definida e estruturada, Jean-Georges Noverre reforma a dança clássica. Defendendo dois princípios absolutamente contestadores, Noverre acredita que o ballet deve narrar uma ação dramática, sem se perder em divertimentos que cortam seu movimento - o ballet de ação -, e que a dança deve ser natural e expressiva. Por isso critica as máscaras, que "abafam os afetos da alma"; os trajes, que dificultam e impedem a liberdade, rapidez e a ação pronta e animada da dança; a técnica, sem significado, idéias ou expressão, fundamentada no virtuosismo excessivo, e a organização das óperas (ballets) com as entrées destinadas às dançarinas principais.

Noverre não apenas critica, como também propõe reformas, que tratam da formação dos bailarinos (caracterizada como uma cultura geral bem vasta, com estudos voltados para poesia, história, pintura, geometria e anatomia), de um estilo liberado para dançar e da composição dos ballets, as quais não devem se limitar "a uma execução mecânica” (Noverre, J. G., citado em Paul Boucier, pag. 174, 2006).

“... Gostaria ainda que os passos fossem executados com tanto espírito quanto arte e que respondessem à ação e aos movimentos da alma do bailarino..."

(Noverre, J. G., citado por Boucier, P., 2006, p. 175).

Em seguida a este período conturbado, porém essencial para o ballet clássico, mais ou menos em 1832, surge o romantismo no ballet. A dança torna-se uma expressão de sentimentos pessoais, sob uma forma diferente dos gestos rigidamente codificados. A técnica do ballet romântico é denominada estilo da alma. Mais do que uma contestação formal, pouco a pouco começava-se a buscar a expressividade, a poesia do corpo e a fluidez dos gestos, muito próximos das idéias dos ballets de ação de Noverre.

Marius Petipa, sem dúvida o maior coreógrafo deste período, transformou o conteúdo do ballet. Herdeiro do ballet de ação, manteve uma trama dramática aliada a 
contos infantis. Suas criações perdem a carga poética e o conteúdo humano para se tornarem pura magia. Em contrapartida, a forma e a mecânica dos passos tornam-se muito precisas; eles são levados ao extremo de sua beleza formal, de sua artificialidade, juntamente com o complemento da alma, que somente os verdadeiros artistas são capazes de incorporar.

A escola clássica francesa pode ser assim definida:

“... buscava uma beleza medida, uma expressão simultânea de elegância e sensibilidade. Na escola acadêmica, acrescentou-se um elemento antinômico, a contribuição italiana, toda a velocidade, virtuosidade de execução, de exteriorização..."

(Bourcier, 2006, p. 222).

A dinâmica do Ballet torna-se, nessa época, uma mecânica quase tão precisa quanto a de um relógio: uma coreografia acadêmica é representante de uma cerimônia de corte, com todas as suas funções, submetida a uma marcação imposta. O pas-de-deux simples ou duplo deve ser incluído em sua forma fixa: conjunto, variações de estrelas, coda; a ele se acrescentam variações para um solo da estrela feminina, cuja duração é estabelecida a partir do renome desta estrela; vêm a seguir as variações menos longas para a segunda categoria da hierarquia, para as primeiras dançarinas, tudo encadeado em movimentos do conjunto, valsas, desfiles, que parecem transpostos da etiqueta imperial.

No academicismo, os passos são levados ao extremo de sua beleza formal, de sua artificialidade. No entanto, quando os bailarinos os executam, carregam-nos de pura poesia. Esse paradoxo entre a execução sistemática dos passos e a sensibilidade poética dos bailarinos, faz com que o expectador seja tomado, primeiramente, por uma sensação de superficialidade que, aos poucos, é recoberta por um sentimento de leveza e majestosidade que a execução poética traz.

"Eis, portanto, um paradoxo evidente: o espectador é atacado, num primeiro momento, por uma sensação superficial, pelo espetáculo de proezas puramente físicas; dificilmente poderá deixar de aplaudir, mesmo antes do fim, 
uma seqüência de trinta e dois fouettés; mas o verdadeiro artista acadêmico alcança regiões bem mais profundas; apresenta ao homem uma imagem ideal dele mesmo: a imponderabilidade, o salto fora do tempo e do espaço, a gratuidade simbólica também são uma liturgia que o coloca em relação com seu sonho permanente de alcançar, ao menos por um instante, a ilusão de ter se tornado um ser imortal. Então, são esquecidos os longos momentos de ensaio, em que o bailarino sofreu o adestramento de eu corpo para a aquisição de uma segurança técnica tal que possa apagar qualquer traço de esforço. A perfeição do movimento, por mais artificial que seja, é um trampolim que lança o espectador para além da aparência material..."

(Bourcier, 2006, p. 222).

Foi somente, o academicismo russo denominado "alma lavada" que conseguiu fundir as contradições solidificadas pela escola clássica francesa e pela escola acadêmica italiana, originando um novo estilo feito de brio, brilho, sensibilidade e delicadeza. Favoreceu, de uma maneira exigente, o exagero nos dois sentidos: agitação sem sentido do corpo.

Atualmente, o ballet clássico encontra-se circunscrito nos moldes do academicismo russo, buscando incessantemente a perfeição. Os treinamentos envolvem repetições de movimentos, para que sejam os mais precisos possíveis. As comparações e os inúmeros elogios para aqueles que executam os passos da maneira mais precisa e poética são inevitáveis, não somente entre os bailarinos, mas também entre os grandes mestres desta arte Compara-se a maneira de executar os passos, a silhueta estética, a graciosidade, a leveza. Compara-se para ser igual ou muito próximo ao impossível de ser atingido. Nada que não seja parecido ou melhor, é suficiente. É preciso mais, mais e mais.

Nesta busca incessante pela perfeição, onde estão o prazer e a alegria? Estão na preparação da maquiagem, no feitio do coque, no calçar das sapatilhas, no pulsar do coração antes de entrar no palco, no anúncio da apresentação, na execução majestosa 
de uma dança e nos incessantes aplausos dos expectadores, atônitos diante de tanta beleza, graciosidade e virtuosismo.

Nos dias atuais, Ballet Clássico e Danças são duas vertentes de uma única arte. As Danças, sejam elas Moderna, Contemporânea, Neoclássica, Jazz, Sapateado, Street Dance procuram, de diferentes maneiras, às vezes sutil e às vezes radical, modificar, ou mesmo contrapor-se à essa rigidez e "coibição de movimentos espontâneos" que é o Ballet Clássico.

Em contrapartida, o Ballet Clássico, na maioria das instituições de dança, mantém-se rigoroso na forma e execução de passos. No entanto, algumas ações pedagógicas tentam, com timidez e sutileza, encontrar uma maneira mais branda, porém competente, de ensiná-lo. Baseiam-se em intervenções pedagógicas que priorizam a aprendizagem de habilidades, com o intuito de uma melhora pessoal, sem comparação com o outro, e a maestria nas tarefas, ou seja, realização das atividades com sucesso.

Esta proposta diferenciada, atualmente é chamada de orientação pedagógica voltada para a tarefa. Ela vem sendo pesquisada e aplicada em contextos esportivos e programas de educação física, na tentativa de minimizar os possíveis prejuízos que as intervenções pedagógicas orientadas para o ego, as quais evidenciam a busca incessante pelo sucesso por meio de atividades de repetição, utilizando-se da comparação entre participantes como forma de incentivo, possam causar nos indivíduos tanto em aspectos físicos quanto afetivo-sociais.

A orientação pedagógica voltada para a tarefa, segundo alguns autores, apresenta ganhos, tais como: aumento da competência pessoal, seleção, por parte dos participantes, de tarefas que desafiam suas habilidades, valorização do processo de aprendizagem, concepção de que o aprendizado tem um fim nele mesmo (Ames \&Ames, 1984), maior entusiasmo na participação das atividades, aumento do esforço na execução das tarefas e maior percepção de competência Yoo (1999), menores índices de falta de motivação (Biddle et al.,2003), manutenção ou aumento da percepção de competência (Hall et al., 1987), entre outros. 
Em contrapartida, a orientação voltada para o ego foca a habilidade individual, o senso de valor próprio e a obtenção de julgamento positivo. A habilidade é evidenciada por fazer melhor que os outros e pela aquisição de sucesso pelo mínimo esforço e o aprendizado é percebido como um caminho para demonstrar capacidade superior.

Alguns estudos relacionam estes dois tipos de intervenção pedagógica - tarefa e ego - com aspectos físicos, psicológicos e sociais dos participantes. Dentre os aspectos físicos mais estudados está a percepção de competência física.

A Percepção de Competência Física é um componente da Noção de Competência Geral que os indivíduos têm sobre si mesmos. Inicialmente, os estudos sobre as teorias motivacionais levaram White (1959) a desenvolver a teoria da EFFECTANCE MOTIVATION (realização de algo, com sucesso), na qual o objetivo principal das ações dos seres humanos é realizar algo com sucesso, sempre.

$\mathrm{Na}$ tentativa de entender e, posteriormente, reformular esta teoria, Susan Harter e Robin Pike, por volta da década de 70, começaram a estudar uma maneira de relacionar o que levava os indivíduos a esta busca intensa pelo sucesso em suas ações, concluindo que a motivação para esta busca é influenciada por muitos aspectos, dentre eles, as percepções do quão competentes as pessoas se sentem para realizar algo.

Sendo assim, em 1980, os dois autores elaboraram uma escala para verificar o quão competentes crianças e adolescentes sentem-se nos diferentes domínios: físico, cognitivo, social e emocional. A escala é denominada de "The Pictorial Scale of Perceived Competence and Social Acceptence for Young Children”.

Verificar o nível de Percepção de Competência Física relacionado à diferentes tipos de intervenção pedagógica pode ser útil para o planejamento e desenvolvimento de aulas de Educação Física e/ou programas de dança e atividades físicas em geral, uma vez que nos apresenta dados concretos sobre a competência física percebida pelos alunos, no decorrer das atividades. 


\section{Justificativa}

As aulas de Ballet Clássico, nas diferentes instituições (escolas de educação infantil, de dança, academias) para crianças, adolescentes ou adultos, são voltadas para o aprendizado, desenvolvimento e perfeita execução de suas habilidades, por meio da utilização de intervenções pedagógicas voltadas para o ego.

No entanto, mais do que a aprendizagem de todos componentes do Ballet Clássico - movimentos, expressão corporal, ritmo, cultura e história -, é necessário levar em consideração os indivíduos que estão dispostos a aprendê-los. Tratando-se de crianças e adolescentes, a maneira de ensinar (intervenção pedagógica) deve levar em consideração não somente os aspectos físicos (execução correta e postura, para a execução de passos), mas outros componentes que fazem parte dos seres humanos cognitivos, sociais e emocionais. A atenção a estes aspectos deve-se, principalmente, ao fato de que as crianças estão em processo de formação do Eu e de consolidação de aspectos da personalidade.

Atividades que priorizam a aprendizagem de diferentes habilidades por meio do esforço na execução das tarefas, que consideram os indivíduos como parte integrante de seu sucesso, não considerando a habilidade como nata e incapaz de melhorar com o treinamento, onde a autocomparação é mais evidente que a comparação com os outros, podem auxiliar no desenvolvimento de aspectos relacionados à noção de competência geral e suas implicações para as ações no decorrer da vida.

\section{Objetivo}

Descrever a influência de uma intervenção pedagógica voltada para a tarefa, na percepção de competência física e na execução de habilidades específicas do Ballet Clássico, em crianças de quatro e cinco anos de idade

\section{Revisão Bibliográfica}




\subsection{Ballet Clássico e Educação Física}

O Ballet Clássico é uma modalidade de dança codificada, ou seja, prédeterminada, a qual nos remete a diferentes culturas, desde o século XII, com um estereótipo propriamente europeu. Ele representa um modelo rígido de formas e passos determinados que devem ser executados com perfeição.

Por tratar-se de execução de movimentos, sejam eles livres ou orientados, o Ballet Clássico pode ser considerado uma atividade que auxilia no aumento do acervo motor, por contemplar diferentes habilidades motoras básicas. Esta atividade pode ser considerada como um forte instrumento para que a criança adquira novos modelos de movimento, uma vez que representa uma cultura de movimento com componentes físicos, culturais e sociais próprios.

Arribas (2002) em seu livro "A Educação Física de três a oito anos", faz um paralelo interessante entre Educação Física e dimensões do ser humano. Mostra que as diferentes atividades físicas, incluindo o Ballet Clássico, podem auxiliar o desenvolvimento motor, por intermédio da potencialização de uma diversidade de experiências que apóiem o aperfeiçoamento dos movimentos e da facilitação de uma série de aprendizagens que permitam a modificação desses movimentos.

De acordo com a autora, a evolução e modificação dos movimentos poderão enriquecê-los e efetivá-los, provocando um melhor relacionamento da criança com seu físico, além de promover a representação de um gesto mais expressivo, possibilitando uma melhor relação da criança com os outros.

\subsection{Ballet Clássico, auto-estima e autoconceito}

$\mathrm{O}$ autoconceito é um julgamento de valor pessoal, que é expresso em atitudes de segurança consigo mesmo (Gallahue, 1987). Ele mostra nossos sentimentos com relação a nós mesmos e também como pensamos que os outros nos vêem. $\mathrm{O}$ autoconceito inclui a consciência de nossas características, capacidades, limitações e utilidades. Quando uma pessoa julga-se capaz de realizar determinada tarefa e não a cumpre com perfeição, ou pelo menos da maneira que esperava realizar, ela 
considera-se inferior, e os sentimentos de culpa, vergonha e depressão podem surgir, causando ansiedade e diminuindo o autoconceito. Confiança e convicção de que se pode forçar ou impor ordem sobre um segmento do universo, são pré-requisitos básicos para um autoconceito positivo e estável.

O autoconceito é aprendido. Nos anos da escola elementar, os pais e professores servem como principais modelos para o desenvolvimento do comportamento das crianças. Eles são um referencial importante, pois, por meio de suas reações as crianças reconhecem como estão influenciando os outros. Por funcionarem como avaliadores do comportamento das crianças, eles dão um significado "moral" ou de "valor" (positivo ou negativo) para as atividades realizadas por elas, o que promove o desenvolvimento do autoconceito (positivo ou negativo).

É difícil apresentar fórmulas para o desenvolvimento de um autoconceito positivo. No entanto, alguns componentes relacionados a ele, como, por exemplo, o relacionamento (indivíduo é uma parte do grupo, sendo aceito e valorizado pelos outros e reconhecido como tal, pelo grupo e por ele mesmo), a competência (autoavaliação da eficiência das nossas realizações), a dignidade (valorização perante você e outros), a auto-aceitação, a aceitação de limites (limites claramente definidos e reforçados) e a individualidade (respeito e tolerância por diferenças individuais), devem estar presentes e relacionados potencialmente. A partir do momento em que o autoconceito positivo e estável alcança seu desenvolvimento, percebemos que as crianças passam a assumir características de segurança e identidade.

O movimento não exerce somente uma forte influência sobre o autoconceito, é também um importante componente dele. Se as habilidades físicas estão pouco desenvolvidas, o efeito negativo sobre o autoconceito é evidente, pois a relação com os indivíduos do mesmo grupo, por existir comparação entre eles, torna-se de submissão, gerando um autoconceito negativo, relacionado com a incapacidade de realização. É necessário que as atividades físicas, propiciem atividades adequadas (progressivas quanto ao grau de complexidade) à idade e ao desenvolvimento das crianças para que elas sintam-se capazes de dominar as condições propostas, 
realizando-as com sucesso e, assim, obtendo melhora e crescimento dentro da fase de desenvolvimento motor em que ela se encontra. É importante, em atividades físicas, a valorização e o incentivo, pois o autoconceito é representado, em grande parte, pelo que os outros pensam de nós. Um autoconceito positivo é sinônimo de uma boa relação social com o meio.

O conceito de auto-estima é bastante amplo e bastante controverso.

Harter (1983) afirma que a auto-estima é a avaliação que a pessoa faz de si mesma nas suas diferentes dimensões. Ela pode ter diferentes avaliações ou percepções de si mesma, em aspectos diversos de sua vida.

Coopershimth (1967, citado por Harter, 1983, p.321) realizou pesquisas sobre a auto-estima de crianças: "Pela auto-estima, referimos para a avaliação que o indivíduo faz e, costumeiramente, mantém com olhar para ele próprio; isso expressa uma atitude de aprovação ou desaprovação, e indica o quanto o indivíduo acredita ser capaz, significante, próspero e merecedor". Em suma, auto-estima, para Coopershimth, é um julgamento pessoal do mérito, que é expresso nas atitudes tomadas pelo indivíduo em direção a si mesmo.

As atividades físicas, incluindo o ballet clássico, auxiliam no desenvolvimento do autoconceito e da auto-estima, positivos ou negativos, dependendo do objetivo e das estratégias utilizadas para alcançar esses objetivos. Assim, atividades adaptadas ao nível de desenvolvimento físico, cognitivo e emocional das crianças, que utilizem estratégias que atendam suas necessidades, com intervenções pedagógicas que priorizem o sentimento de eficiência, eficácia e sucesso, constituem importantes componentes para a formação de um autoconceito e auto-estima positivos.

\subsection{Percepção de Competência}

White (1959, citado por Harter, 1978, p. 34) desafiou todas as teorias motivacionais anteriores, tornando clássico o conceito de competência. Sua tese baseia-se na inferência de que todas estas ações (que ações?) manifestam um desejo rumo à competência. A última proposta de White foi descrever, mais especificamente, 
a possível natureza do aspecto motivacional da competência. Para White, a motivação é o que faz as pessoas buscarem a competência na relação com o ambiente, originando, assim, um sentimento de eficácia e satisfação. Desta forma, o autor propôs um novo constructo motivacional, denominado EFFECTANCE MOTIVATION (realização de algo, com sucesso). Este termo foi escolhido pelo autor, pois parecia ser um neologismo apropriado, que alude às inúmeras facetas da motivação: o desejo do organismo em produzir um EFEITO no ambiente; o objetivo de interagir efetivamente ou competentemente com o ambiente; e o resultante sentimento de eficácia.

\begin{abstract}
"O principal constructo da competência ou aquele que mais afeta a motivação é que uma criança é compelida a repartir efetivamente com o ambiente e então engajar em tentativas de sucesso. Então, com o sucesso nessas tentativas, a criança experiência sentimentos de prazer ou eficácia inerentes, os quais conseqüentemente mantêm ou aumentam a motivação no indivíduo".
\end{abstract}

(White, 1959, citado por Harter S., 1978, p. 34).

Harter (1978) refinou e estendeu o Modelo de Influência na Motivação de White, estudando maneiras de relacionar a motivação e o desenvolvimento. Como Weiss et al. (1985) sugeriu, este refinamento e extensão pavimentaram o caminho para o uso de testes empíricos por meio da definição dos componentes e formulação de escalas de descrição do indivíduo para acessar constructos integrais para o modelo.

Susan Harter,e Robin Pike em 1984, construíram uma escala para medir a percepção de competência e a aceitação social em crianças, cujo objetivo foi fornecer subsídios para diferentes profissionais trabalharem em direção ao aumento de ambos os conceitos, uma vez que eles constituem um dos domínios que favorecem a Effectance Motivation.

A Percepção de Competência é um conceito que vem sendo estudado há muitos anos, e significa uma dimensão da auto-avaliação que os indivíduos fazem de si 
próprios. A Percepção de competência física é um dos domínios da Percepção de Competência, que nos possibilita compreender o quão capazes e eficientes os indivíduos se sentem para realizar diferentes tarefas motoras.

A percepção de competência refere-se às concepções individuais de quanto mais ou menos habilidosos somos (Nicholls, J. G., 1992 citado por Valentini, 2000, p. $6)$.

No modelo de Harter (1978), a competência percebida é vista como multidimensional, sendo demonstrada como cognitiva, social ou interpessoal, e física.

A teoria da competência percebida foi desenvolvida como chave principal da teoria de cognição social, e é uma das variáveis mais utilizadas em pesquisas sobre motivação. (Harter1978).

A competência percebida é um importante mediador para manter e/ou aumentar a motivação na criança. A combinação de alta percepção de competência ou elevada auto-estima e uma percepção interna de controle aumenta o sentimento de eficácia e prazer intrínseco da criança. No entanto, a combinação de baixa percepção de competência ou baixa auto-estima e uma percepção externa de controle podem conduzir para a ansiedade na maestria e, assim, diminuir a motivação das crianças (Harter,1978).

\subsection{Percepção de competência e influência de diferentes intervenções pedagógicas}

Atualmente, muitos pesquisadores estudam diferentes técnicas de aprendizagem, utilizadas em diferentes tipos de aulas. Algumas delas são voltadas para a execução de habilidades básicas ou específicas, por meio de uma intervenção pedagógica diretiva, mostrando as maneiras de execução destas tarefas e as melhores formas de alcançar os objetivos propostos, e outras são voltadas para o encontro das melhores soluções para se alcançar o objetivo proposto. $\mathrm{O}$ primeiro tipo de intervenção pedagógica é considerada uma intervenção orientada para o desempenho, 
e a segunda, uma intervenção orientada para a maestria (Ames \& Archer, 1988).

Maestria e Desempenho são dois tipos de intervenção pedagógica opostas, que se diferem por três motivos: como são percebidos e avaliados o aprendizado, o esforço e o sucesso; as razões para a aproximação e engajamento nas atividades; e o que o indivíduo pensa sobre ele mesmo, sobre as tarefas e sobre os resultados das tarefas.

Ames \&Ames (1984) relacionam esforço e resultado na maestria, ou seja, de acordo com eles, o esforço conduz para o progresso pessoal e para a maestria em determinada tarefa.

Ames (1992, citado por Valentini, 2000, p. 1) mostra que os indivíduos orientados para a maestria buscam o desenvolvimento de novas habilidades, aumentam a competência pessoal ou atingem um senso de maestria, baseados na internalização de determinados padrões. Estes indivíduos selecionam tarefas que desafiam suas habilidades e aumentam sua competência. Um grande valor é dado no processo de aprendizagem e o aprendizado é visto como um fim nele mesmo

Ames (1992) fala sobre o objetivo central da técnica voltada para o desempenho: foca a habilidade individual e o senso de valor próprio, a habilidade é evidenciada por fazer melhor que os outros e pela aquisição de sucesso pelo mínimo esforço. Habilidade e esforço são vistos como inversamente relacionados. Indivíduos orientados para o desempenho buscam obter um julgamento positivo e evitam julgamentos negativos sobre suas performances; eles mesmos comparam suas performances com os outros, (Dweck, 1986). Além disso, buscam reconhecimento público. O aprendizado é percebido como um caminho para demonstrar capacidade superior.

Alguns estudos realizados mostram resultados favoráveis na adoção de técnicas voltadas para a maestria.

Ames (1984) mostrou que as crianças envolvidas em aulas com um tipo de orientação voltado para a maestria demonstram, significativamente, mais esforço relacionado à cognição e à execução das tarefas do que as crianças em aulas com um 
tipo de orientação pedagógica voltada para o desempenho. De acordo com o autor, elas usam estratégias efetivas de aprendizado, auto-instrução, e tipos de pensamento de automonitoramento, mais vezes do que as crianças engajadas em atividades voltadas para o desempenho. Grupos orientados para a maestria focam no seu próprio esforço e procuram caminhos para manter ou aumentar suas performances, com uma visão em si e não no grupo.

Dweck et al. (1988), elaboraram um quadro, mostrando os mecanismos cognitivos e afetivos de acordo com o tipo de intervenção pedagógica.

\section{Objetivos de Desempenho Objetivos de}

\section{Aprendizagem/Maestria}

1. Menor crença na eficácia do Crença na eficácia do esforço:Esforço esforço, dando baixa atribuição à na auto instrução, ao invés de baixa habilidade; atribuição à habilidade; regras positivas enfatizam a utilidade do esforço

2. Retirada defensiva de esforço: Esforço é sinônimo de exigência da Esforço confirma baixo julgamento da tarefa e objetivos

habilidade; regras inversas criam conflitos entre exigências da tarefa e objetivos

3.Atenção dividida entre objetivo Atenção intensificada para a tarefa (preocupação com o resultado) e que seve, diretamente, ao objetivo tarefa (formulação e execução de estratégias)

4. Influência negativa pode interferir Influência da tarefa na concentração ou induzir a retirada

5. Novas recompensas intrínsecas de Contínuas recompensas intrínsecas esforço para sustentar o processo para se engajar em desafios, com esforço

Figura 1 - Mecanismos cognitivos e afetivos e tipo de intervenção pedagógica

Valentini (2000) descreve que a adoção de técnicas voltadas para a maestria pode levar os indivíduos para atitudes positivas em direção ao aprendizado. Eles focam na maestria de habilidades e no aumento de sua habilidade, baseados nos seus próprios padrões. Eles relacionam o sucesso com o esforço. No entanto, de acordo 
com a autora, indivíduos orientados para o desempenho adquirem atitudes negativas para o aprendizado, quando se deparam com a dificuldade.

Tzetzis et al (2002) no estudo realizado com cento e doze crianças (meninos e meninas) entre nove e doze anos de idade, mostraram que as aulas de Educação Física que primaram pelo ambiente de aprendizagem e não de performance, criaram condições apropriadas para que os estudantes pudessem se concentrar na melhoria de seus desempenhos e, além disso, gastar mais tempo, e persistirem mais, nas atividades com um alto grau de dificuldade.

O estudo objetivou examinar a relação da atividade física dos estudantes durante as aulas de educação física com o tipo de orientação pedagógica destinada a eles. Foi preenchido um questionário que pudesse avaliar, segundo a percepção dos estudantes, em que tipo de intervenção pedagógica estavam inseridos. O instrumento utilizado foi "The Task and Ego Orientation Sport Questionnaire" (Duda, 1992). Para avaliar a atividade física dos alunos durante as aulas de educação física, foi utilizado o "Computer Sciense and Applications - CSA (Trost et al., 1998).

Os resultados mostraram que os estudantes que perceberam que o tipo de intervenção pedagógica estava voltado para a tarefa permaneceram mais tempo nas atividades mais complexas e difíceis, quando comparados com os estudantes que perceberam o tipo de intervenção voltada para o ego. Além disso, mostraram que o ambiente de aprendizagem nas aulas de educação física, especialmente na educação infantil, cria condições para os estudantes esforçarem-se na tentativa de melhorar seus desempenhos e gastar mais tempo nas atividades complexas.

White et al. (2004) estudaram a percepção dos pais sobre as causas do sucesso no esporte e a relação com as metas dos atletas e suas crenças pessoais sobre o mesmo tema. Participaram do estudo cento e oitenta e três atletas de times de diferentes esportes (basquete, voleibol, futebol, basebol), da região de Midwest, nos Estados Unidos. A média de idade entre as meninas foi de 15,44 e entre os meninos de 14,03 anos.

As metas estabelecidas pelos atletas para atingir os objetivos das atividades foi 
medida através do "The Task and Ego Orientation in Sport Questionnaire" (Duda and Nicholls, 1992). As crenças pessoais sobre a causa do sucesso nos esportes foi verificada com "Beliefs about the Causes of Sport Success Questionnaire" (Duda and Nicholls, 1992). A percepção da crença dos pais sobre as causas do sucesso nos esportes foi mensurada por meio da modificação de dois itens do questionário utilizado com os atletas.

Os resultados mostraram que os atletas altamente orientados pela tarefa e moderadamente pelo ego, acreditam que o esforço conduz ao sucesso nos esportes e que seus pais apresentam o mesmo pensamento. Em contrapartida, os atletas orientados pelo ego, em acordo com seus pais, acreditam que o sucesso no esporte é alcançado por meio do erro dos outros, de fatores externos como sorte, e da demonstração de superioridade com relação às habilidades.

Brunel (1999) estudou a relação entre o tipo de orientação dos indivíduos (tarefa ou ego) e a percepção do clima motivacional na motivação intrínseca. O objetivo do estudo foi relacionar a percepção do clima motivacional com o tipo de orientação dos indivíduos (tarefa ou ego) nos índices de motivação intrínseca, extrínseca e falta de motivação. Participaram do estudo cento e sessenta estudantes (101 homens e 59 mulheres) do primeiro ano da faculdade de educação física, que faziam parte do curso de badminton e que praticavam algum tipo de esporte, mas que nunca haviam tido nenhum contato com essa modalidade. A média de idade foi de 18,75 anos.

Após doze semanas no curso de badminton, os participantes foram convocados a realizarem uma bateria de testes. Na última aula do curso, os pesquisadores distribuíram os testes realizados anteriormente, cujo objetivo foi verificar o que eles sentiram no decorrer do curso, como maneira de direcionar possíveis modificações nele. Para descobrir qual o caminho em que o indivíduo sente-se mais motivado, se por uma orientação voltada para a tarefa, ou se para uma orientação voltada para o ego, o "Questionnaire dês Perceptions de Succès en Sport" foi utilizada. A motivação 
intrínseca foi mensurada por meio da "Echelle de Motivation dans les Sports". O clima motivacional foi verificado com a "Echelle de Perception Du Clima Motivationnel".

Os resultados mostraram que, quando os estudantes percebem um clima motivacional voltado para a maestria, crescimento pessoal ou esforço na realização das atividades, eles focam no interesse intrínseco pelo aprendizado ou aquisição de novas habilidades, acreditando que uma boa marca é obtida por meio de esforço e com a cooperação dos outros. Sendo assim, quando o clima motivacional é percebido como voltado para a maestria, os estudantes exibem uma regulação interna que consiste em se esforçar para ir às aulas, como forma de se proteger contra possíveis maus desempenhos. Em contrapartida, quando percebiam um clima motivacional voltado ao desempenho, enfatizando resultados normativos, ou seja, de acordo com a média dos atletas, onde a quantidade de pontos feitos era considerado o melhor indicador das habilidades, os participantes apresentaram falta de motivação.

Ommundsen et al. (1998), no estudo realizado com estudantes Noruegueses, objetivaram relacionar a percepção do clima motivacional com aspectos cognitivos e afetivos. Participaram do estudo cento e quarenta e oito estudantes (70 homens e 78 mulheres) da Universidade de Esporte de Educação Física da Noruega, com média de idade de 21,2 anos. Todos eles tinham experiência em times esportivos participantes, no mínimo, dos clubes de elite locais.

Para acessar a percepção do clima motivacional foi utilizada a versão norueguesa do "The Perceived Motivational Climate in Sport Questionnaire" (Seifriz et al., 1992; Walling et al., 1993; Roberts and Ommundsen, 1996). Para verificar em qual tipo de orientação os atletas incluíam-se, foi utilizada "The Perception of Success Questionnaire” (Roberts and Ommundsen, 1996). O nível de satisfação dos interesses dos atletas também foi um componente importante para somar-se aos aspectos afetivos analisados na pesquisa. Para verificar o grau de satisfação intrínseca e o interesse pelos esportes, os participantes responderam a oito (8) itens, baseados na pesquisa de Duda e Nicholls, (1992). 
Outro componente que fez parte dos aspectos afetivos da pesquisa foram as fontes de satisfação e interesses nos esportes. As percepções das fontes de satisfação nos esportes foram determinadas por três (3) sub-escalas. Um componente da análise cognitiva da pesquisa relacionou-se às estratégias dos estudantes para alcançar seus objetivos. Os dados foram coletados utilizando-se vinte (20) itens relacionados à aquisição de alguns estudos anteriores a esse, do mesmo autor. $\mathrm{O}$ último componente a ser avaliado foram as razões para se envolver em esportes de alto nível: status social, responsabilidade social e vida saudável. Esse componente foi analisado por meio de dezoito (18) itens da pesquisa realizada por Duda (1989).

Os resultados mostraram que a percepção de um clima motivacional voltado para a tarefa no esporte, está relacionada, de maneira positiva, com a orientação individual (de cada um) para a tarefa. Este resultado provém dos sentimentos de maestria, progresso e aprendizado, originados pelas atividades orientadas para a tarefa. Os atletas que percebem uma estrutura situacional de metas orientadas para a maestria apresentaram aquisição de estratégias, disposição para aprender com a prática e para continuar praticando esporte. Além disso, eles relataram o envolvimento com o esporte como sendo importante para o desenvolvimento de habilidades básicas para a vida tais como o aumento da consciência sobre saúde e o interesse contínuo pelo esporte. Em contraste, os estudantes que perceberam o clima motivacional voltado para o desempenho, apresentaram menos satisfação nas atividades esportivas, tenderam a fugir da prática e viram o esporte, primeiramente, como uma maneira de ascensão social e reconhecimento.

Outro ponto interessante desta pesquisa foi a relação estabelecida entre clima motivacional e satisfação. Os estudantes que participaram das aulas voltadas para a maestria, em contextos que enfatizavam e focavam no progresso pessoal, relataram sentimentos de satisfação com seus resultados, não somente pelo aumento do empenho nas atividades, mas também, pela melhora nas habilidades específicas por adquirirem o "seu melhor pessoal".

Em contrapartida, quando os estudantes perceberam um clima motivacional 
orientado para o desempenho relataram diminuição no nível de envolvimento e aumento no nível de pressão e tensão. Em função do clima motivacional orientado para o desempenho focar na superioridade da habilidade e na supressão dos outros, os atletas têm pequeno controle na criação e modificação do clima e, conseqüentemente, menores índices de satisfação.

Com relação à aquisição de estratégias, os resultados mostraram uma relação estreita entre clima motivacional orientado para a maestria e a aprendizagem de estratégias nas aulas, sugerindo que esse tipo de intervenção é importante para o desenvolvimento de estratégias que se adaptam às diferentes situações do esporte de competição. Uma atmosfera orientada para o desempenho pode interferir na atenção, concentração e implantação de estratégias efetivas na tarefa dos atletas, aumentando a ansiedade com possíveis falhas de atuação.

Morgan (2002), estudaram os efeitos da manipulação do clima motivacional nas aulas de Educação Física em crianças com doze anos de idade e demonstraram que existem diferenças significantes no pré e no pós-teste, das crianças que participaram do grupo voltado para a maestria. No que diz respeito à escolha pelas tarefas mais complexas, e suas respostas cognitivas e afetivas, as crianças apresentaram-se mais aptas, cognitiva e afetivamente, para realizarem as tarefas difíceis, sem medo do fracasso. Sendo assim, o estudo sugere que nas técnicas voltadas para a maestria, os alunos escolhem tarefas mais complexas e tentam aumentar a qualidade de seus desempenhos, podendo, desta forma, usar o seu verdadeiro potencial, sem medo do julgamento dos outros.

Alguns estudos demonstram a diferença dos diversos tipos de intervenção pedagógica (maestria e desempenho) na noção de competência, em participantes de atividades físicas ou esportes.

Yoo (1999) realizou um estudo que tinha como proposta, investigar como as orientações pedagógicas (tarefa ou ego) e a percepção de clima motivacional (aprendizagem ou desempenho) relacionavam-se com motivação intrínseca 
(interesse, esforço, competência e tensão), auto-estima, adesão para a atividade e avaliação da habilidade, num contexto de educação física escolar. Participaram do estudo 218 homens, com média de 21,4 anos de idade, estudantes da Chung-Ang University, em Seoul, na Coréia. Os participantes foram divididos em grupos de iniciação esportiva: tênis, golfe, boliche e natação. As aulas tinham como objetivo, melhorar a habilidade básica esportiva, em 12 (doze) semanas, com duas horas de aula.

Os resultados mostraram que a orientação voltada para a tarefa relacionava-se positivamente com o clima motivacional voltado para a aprendizagem, ou seja, que as aulas onde o clima motivacional mostrava-se voltado para a aprendizagem, apresentavam atividades norteadas pela descoberta orientada. Por outro lado, a orientação voltada para a tarefa relacionava-se negativamente com as aulas cujo clima motivacional estava voltado para o desempenho. As aulas cuja orientação pedagógica estava voltada para o ego, apresentaram uma relação positiva com o clima motivacional voltado para o desempenho e uma relação negativa com o clima motivacional voltado para a aprendizagem. O clima motivacional voltado para aprendizagem apresentou-se positivamente relacionado com a avaliação no nível de habilidade e da adesão às atividades das aulas, enquanto o clima motivacional voltado para o desempenho não apresentou correlação significativa.

Desta forma, Yoo (1999) concluiu que os estudantes que foram orientados para tarefa e que perceberam em suas aulas um clima motivacional voltado para a aprendizagem expuseram com mais entusiasmo suas experiências, esforços e percepção de competência. Por outro lado, a orientação voltada para o ego e o clima motivacional voltado para o desempenho mostraram-se negativamente correlacionados com a motivação intrínseca, uma vez que os participantes não se sentiam motivados a continuar praticando a atividade, em função do sucesso estar baseado em uma suposta habilidade superior entre os participantes, da ênfase à competição envolver todas as atividades das aulas e do sentimento de pressão para ser sempre o melhor, no decorrer das aulas. 
Portanto, quando os estudantes percebem um clima motivacional voltado para a aprendizagem e uma orientação pedagógica para a tarefa, eles melhoram suas habilidades básicas, nos esportes selecionados, o que aumenta sua adesão às atividades das aulas.

Nicholls (1989, citado por Biddle et al., 2003, p. 978) relacionou o tipo de intervenção (tarefa ou ego) com a falta de motivação, sugerindo que as orientações voltadas para a tarefa são, negativamente, relacionadas com a falta de motivação, e que as atividades voltadas para o ego estão positivamente relacionadas com a falta de motivação, principalmente, nos indivíduos com baixa percepção de competência.

Biddle et al. (2003) encontraram resultados congruentes aos sugeridos por Nicholls (1989), ou seja, o tipo de intervenção, bem como o grau de percepção de competência, influenciam, diretamente, na falta de motivação. As atividades voltadas para a maestria apresentaram menores índices de falta de motivação, principalmente nos indivíduos com alta percepção de competência. No entanto, os indivíduos com baixa percepção de competência, engajados em atividades voltadas para a performance, apresentaram maiores índices de falta de motivação.

O objetivo deste estudo foi verificar a relação entre crença de ser habilidoso, com tipos de intervenção pedagógica, percepção de competência e falta de motivação para a prática de atividades físicas.

O estudo envolveu 2696 participantes, entre os quais 1566 eram meninas e 1453 meninos, com média de idade de 12,9 anos, estudantes de 49 escolas da Inglaterra, os quais tiveram aulas de educação física no sétimo, oitavo e nono anos de vida. Para as informações sobre o tipo de orientação pedagógica, foi aplicado uma versão do teste "Task and Ego Orientation in Sport Questionnaire” (Duda et al., 1992; Duda and Whitehead, 1998). A crença em ser habilidoso foi verificada por meio de um teste modificado e revalidado pelos mesmos autores denominado "Conceptions of the Nature of Athletic Ability Questionnaire". A percepção de competência foi avaliada pelos seis itens de competência esportiva do "Physical Self-Perception Profile for Children" (Whitehead, 1995). Por último, a falta de motivação para a 
prática esportiva foi avaliada por três itens modificados por Goudas et al. (1994) da “Academic Motivation Scale" (Vallerand et al., 1992,1993).

Para a análise dos resultados, os autores consideraram a percepção de competência como um moderador, ou seja, os participantes foram divididos em dois grupos - baixa e alta percepção de competência. Os resultados mostraram que a falta de motivação está direta e indiretamente relacionada com a crença em ser habilidoso, ou seja, indivíduos mais habilidosos sentem-se mais motivados para a prática de atividades físicas. A falta de motivação também foi analisada sob outra perspectiva, considerando a baixa e alta percepção de competência como mediadores. Nesta análise os autores apuraram que a falta de motivação foi mais relevante para o grupo de baixa percepção de competência. Segundo os autores, esta constatação era esperada uma vez que a falta de motivação é sempre muito menor para aqueles que se sentem altamente competentes.

Analisando o tipo de intervenção com a percepção de competência, os resultados mostraram que a orientação voltada para a tarefa mostrou ter pequena influência, principalmente em indivíduos com alta percepção de competência e mostrou média influência, no grupo de baixa percepção de competência. No entanto, a orientação voltada para o ego, nesse estudo, não apresentou relação direta com a falta de motivação.

Com relação à crença de ser habilidoso, os participantes de aulas de educação física com orientação voltada para a tarefa, apresentavam um aumento significativo quando relacionados com os alunos cuja orientação foi voltada para o ego, os quais mostraram acreditar que ser habilidoso é algo nato. Para os indivíduos participantes do grupo de alta percepção de competência, essa relação apresentou-se ainda maior, ou seja, a grande maioria acreditava que a habilidade é algo nato, dado a alguns, como presente.

$\mathrm{Na}$ terceira etapa do mesmo estudo, Biddle et al. (2003) relacionaram o prazer pela atividade à percepção de competência, tipo de intervenção pedagógica e crença de ser habilidoso. 
Os resultados mostraram que os sentimentos de prazer pela atividade, são mais aparentes quando os indivíduos participam de atividades voltadas para a tarefa e quando acreditam que as habilidades esportivas podem ser desenvolvidas e melhoradas com o treinamento. Além disso, os resultados mostraram que indivíduos, com alta percepção de competência, participantes de atividades voltadas para o ego, apresentam prazer na realização da atividade. No entanto, indivíduos com baixa percepção de competência envolvidos nas mesmas atividades, relacionam-se, negativamente, com a realização das tarefas.

Biddle et al. (1999) relacionaram a percepção de competência, os tipos de intervenções pedagógicas e a crença de ser habilidoso, com a permanência nas atividades físicas ou esportivas. O estudo contou com 723 crianças entre 12 e 16 anos de idade, estudantes de 28 escolas da Hungria. Todos eles eram voluntários, conheciam muitas habilidades esportivas e mostravam-se interessados em esporte e educação física.

Os instrumentos utilizados foram: "Conceptions of the Nature of Atlhetic Ability Questionnaire" (Sarrazin et al, 1996), sem as modificações realizadas para o estudo acima realizado em 2003, para crença em habilidades esportivas, "Task and Ego Orientation in Sport Questionnaire" (Duda et al., 1998), para o tipo de intervenção pedagógica, os seis itens da competência física do "Physical SelfPerception Profile" (Fox et al., 1989), para a percepção de competência e, por último, um questionário formado por uma única questão, no qual as crianças respondiam sobre a intenção em permanecer nas atividades físicas ou esportivas, e que foram avaliados por meio de uma pontuação da escala LiKert. A percepção de competência foi relacionada com a motivação e, portanto, com a continuidade na realização de atividades físicas, ou seja, indivíduos que se sentem competentes permanecem mais tempo praticando atividades físicas. Indivíduos participantes de atividades voltadas para a maestria tornam-se ativos por um tempo maior, se relacionados com os participantes de atividades voltadas para a performance, o que pode ser explicado pelo fato de que as atividades voltadas para a maestria possibilitam o progresso 
pessoal, pelo esforço.

Valentini (2000), em sua dissertação, revela que nas atividades ministradas com técnicas voltadas para o desempenho, as crianças apresentam uma percepção de competência física mais baixa do as crianças que participam de atividades voltadas para a maestria.

Reinboth, M.et al. (2006), num estudo longitudinal, examinaram, a relação entre as mudanças na percepção do clima motivacional (aprendizagem e desempenho) com as mudanças na necessidade de satisfação dos atletas e nos índices de bem-estar físico e psicológico, em atletas de uma universidade britânica, durante uma temporada de jogos universitários. Participaram do estudo 128 universitários, com média de idade de 19,56 anos, participantes dos times de futebol, rugby, netball, lacrosse e hóquei. Duas coletas de dados foram realizadas, no decorrer do estudo, uma no início da temporada (1-7 semanas) e outra após a temporada (6-8 semanas).

A coleta de dados consistiu em: análise da percepção do clima motivacional, realizada por meio do instrumento Perceived Motivational Climate in Sport Questionnaire-2 (PMCSQ-2; Newton, et al., 2000), avaliação das necessidades básicas para a autonomia no domínio físico, realizada do IPLOC - quatro questões para verificar aspectos básicos da autonomia (ex. "No futebol, eu sinto que minhas escolhas e ações são baseadas nos meus próprios interesses e valores") e seis questões para verificar a possibilidade de escolha/decisão, como parte da percepção da autonomia, satisfação das necessidades para a competência (o que eu preciso para me sentir competente), avaliada através de cinco itens, retirados da sub-escala da percepção de habilidade do "Intrinsic Motivation Inventory" (McAuley, Duncan, \& Tammen, 1989), satisfação das necessidades de relacionamento pessoal no esporte, analisada por meio de cinco itens do "Acceptance subscale of the Need for Relatedness Scale" (Richer \& Vallerand, 1998) (versão validada para esporte e atividade física) e, por último, a análise das variáveis de bem e mal -estar nos esportes, por seis itens da versão de "Subjective Vitality Scale", que tem como objetivo medir o quanto os participantes sentem alertas e com vigor, físico e mental, 
quando participam de seus esportes.

Os resultados mostraram que houve um aumento na satisfação das necessidades de autonomia em todos os conceitos analisados, na competência e no relacionamento (com o time ou com o técnico), os quais foram relacionados pela percepção dos atletas, de que o técnico enfatizava o clima motivacional voltada para a aprendizagem. A percepção de que o técnico enfatizava o clima motivacional voltado para o desempenho, teve um impacto grande no relacionamento do time: rivalidade, reconhecimento somente pelo talento e não pelo esforço, desdém.

Neste estudo, a percepção de um clima motivacional voltado para o desempenho não emergiu como algo negativo para as necessidades básicas de autonomia e competência. $O$ fato da amostra abranger atletas dos times da universidade, isto é, alunos que treinam e que têm um nível, muitas vezes, profissional e, portanto possuem autonomia e poder de decisão, durante o jogo, explica esta falta de relação.

A satisfação das necessidades foi altamente relacionada com o aumento da vitalidade. Tal resultado pode ser explicado pela proposta de Ryan e Frederick (1997), segundo a qual a vitalidade subjetiva não está somente relacionada com fatores psicológicos, mas também pelo significado subjetivo dos fatores físicos, no Eu. A satisfação das necessidades também foi relacionada de maneira positiva, com o bemestar psicológico, ou seja, quando, dentro das atividades de treinamento, as necessidade de autonomia e competência foram atendidas, os atletas sentiam um bem-estar psicológico.

Bois et al. (2005) investigaram, por meio de um estudo longitudinal - cerca de 12 meses - como o fato dos pais serem indivíduos fisicamente ativos e suas crenças sobre a competência física dos filhos, poderia interferir na própria percepção de competência e na quantidade de dedicação, as crianças, para a atividade física. Outro objetivo da pesquisa foi verificar, caso exista influência nestes dois aspectos para as crianças, se pai ou mãe têm maior influência. A amostra era composta por 152 famílias de quatro cidades diferentes da França. Apenas uma criança por família, num 
total de 84 meninas e 68 meninos, com idade entre 9 e 11 anos de idade (média de 9,56 anos). As mães tinham em média 38,04 anos de idade e os pais 39,8 anos.

Os instrumentos utilizados foram: "Child's perceived competence in physical activity" (Sarrazin, Bois, \& Trouilloud, 2000), para analisar a percepção de competência física das crianças; "Child's physical activity duration" (Haaro, 1997; Manios, Kafatos, Markakis, 1998), para verificar o tempo despendido, pelas crianças, nas atividades físicas; "Questionnaire on mother's perceptions of their child's physical competence" (Sarrazin, Bois, \& Trouilloud, 2000), para verificar a percepção dos pais com relação à competência física dos filhos; e a atividade física dos pais, relatada por meio de uma lista de atividades que eles tinham que identificar as atividades das quais eles participaram, bem como o tempo de participação. Foram realizadas duas coletas de dados: uma em outubro de 2000 e outra em outubro de 2001. Na primeira coleta, foram obtidos os dados de todas as variáveis dos pais e a idade, sexo e percepção de competência inicial. Um ano depois, a atividade física das crianças e a percepção de competência atual, foram mensuradas. As crianças completaram os questionários em pequenos grupos, e os pais completaram seus questionários em casa.

Os resultados mostraram que as mães, não os pais, envolvidos em atividades físicas, foram relacionadas com o envolvimento de suas crianças nas atividades físicas. Desta forma, conclui-se que o envolvimento das mães em atividades físicas é mais saliente para as crianças com idade entre 9 e 11 anos do que o envolvimento dos pais, provavelmente porque estão mais envolvidas, no dia-a-dia, na escolha de suas crianças. A percepção da competência física, somente das mães com relação aos seus filhos, influenciou na percepção de competência física das crianças. Este resultado mostrou-se independente do nível inicial de percepção de competência física das crianças, da idade e do sexo. Uma possível explicação pode estar relacionada com o fato de que a influência social das mães é maior, nas crianças mais jovens, devido seu grande envolvimento nas atividades diárias de seus filhos.

Outro resultado indicou que a percepção da competência física das crianças foi 
relacionada com o envolvimento, delas, em atividades físicas, ou seja, crianças que participam de atividades físicas apresentam maior nível de percepção de competência física do que as crianças que não participam de nenhuma atividade. A percepção da competência física dos filhos, pelos pais (não somente pelas mães), afetou diretamente a atividade física das crianças. Este resultado mostra que a percepção dos pais afeta a atividade física de seus filhos por outras vias: ela afeta a natureza das atividades oferecidas por eles, bem como a frequiência delas, ou seja, dependendo da quantidade das oportunidades de jogos, brincadeiras e atividades dadas pelos pais, as crianças dão mais ou menos valor a elas.

Weiss et al. (1985, 1986) sugeriram que altos níveis de percepção de competência aumentam diretamente a preferência das crianças para desempenhos com maiores dificuldades, escolha de tarefas, e desenvolvimento do senso de habilidade interna. Além disso, indivíduos com alta auto-estima foram mais persistentes (em tempo) nas atividades e mais aptos para adquirir maestria, nas atividades complexas. Nesses casos, as crianças que se percebem competentes, são mais facilmente engajadas e persistem, por mais tempo, nas atividades esportivas.

\subsection{TARGET}

Uma maneira de verificar a tendência do clima motivacional, de acordo com a estruturação do ambiente é o instrumento denominado TARGET. Desta forma, através de seis dimensões (tarefa, autoridade, reconhecimento, agrupamento, avaliação e tempo), classifica-se as aulas em orientações pedagógicas voltadas para a tarefa, quando o clima motivacional é voltado para a aprendizagem ou em orientações pedagógicas voltadas para o ego, quando o clima motivacional é voltado para o desempenho. As dimensões serão explicadas a seguir.

T (task - tarefas) - A estrutura das tarefas incluem o conteúdo e seqüência do currículo, desígnio dos trabalhos de classe e de casa, dificuldade das tarefas e o material requerido para o término das tarefas. Essas estruturas de tarefas educacionais 
determinam, largamente, a variedade de opções pelas quais os estudantes selecionam seus interesses especiais (Epstein, 1988, citado por Valentini, 2000, p. 25).

É sugerido que os professores construam estruturas de tarefas que provenha desafios para os diferentes níveis de estudantes, de forma a nutrir objetivos de maestria em todos eles. Criar tarefas desafiadoras que não sejam tão difíceis ou tão fáceis para os estudantes, pois o professor conhece o nível de habilidade e o conhecimento prévio dos alunos (Valentini, 2000).

A (autority structure - autoridade) - A estrutura de autoridade da sala de aula influencia a natureza da decisão tomada entre professores e alunos. Em muitos tipos de aulas, professores e alunos compartilham responsabilidades pela escolhas feitas, dando direções, monitorando trabalho, fixando e reforçando metas, estabelecendo e oferecendo recompensas e avaliando o sucesso.

R (recognition structure - reconhecimento) Concerne no uso formal e informal de recompensas, incentivos e elogio nas aulas.

Manter ou impulsionar a motivação dos estudantes pode ser alcançado por:

1. Reconhecimento e recompensa para os progressos individuais dos alunos;

2. Criação de oportunidades de recompensas;

3. Dar reconhecimento e recompensas individualmente, para que desta forma, seus valores não derivem dos outros;

4. Focar no auto valor das crianças.

G (grouping structure - estrutura do grupo com o qual se trabalha) A estrutura de grupo determina se, como e porque os estudantes que têm características particulares similares ou diferentes (gênero, raça, habilidade, objetivos ou interesses) devem ser trazidos para próximo do professor para que ele possa dar as instruções individualmente ou se ele pode receber as instruções como todos os outros. 
E (evaluation structure - avaliação) Uma estrutura de avaliação efetiva é aquela que não julga os indivíduos em certos ou errados mas, que os fazem compreender seus próprios esforços, habilidades e progresso.

Avaliações em técnicas de ensino voltadas para a maestria, envolvem critérios de progresso individual, feedback individual, auto-avaliação privada dos indivíduos participantes e oportunidades para que todos possam vivenciar o sucesso, de acordo com seus próprios esforços.

T (time structure - tempo) O tempo para as atividades deve estar de acordo com o trabalho programado englobando as explicações das tarefas e o tempo para que os indivíduos possam aprendê-la. É importante que o professor reserve tempo suficiente para que todos indivíduos possam aprender e completar as tarefas propostas.

O quadro abaixo apresenta, resumidamente, as descrições do TARGET e as estratégias para que as aulas possam ser caracterizadas voltadas para a tarefa.

\begin{tabular}{|c|c|}
\hline TARGET & Estratégias \\
\hline $\begin{array}{l}\text { TAREFA }-\mathrm{At} \\
\text { tarefas e trabalh }\end{array}$ & $\begin{array}{l}\text { 1. Variedade de atividades, desafio } \\
\text { individual e envolvimento ativo; } \\
\text { 2. Auxílio das crianças e meta em } \\
\text { curto prazo. }\end{array}$ \\
\hline $\begin{array}{l}\text { icipação dos } \\
\text { le instrução. }\end{array}$ & $\begin{array}{l}\text { 1. Envolvimento das crianças na } \\
\text { tomada de decisão e na elaboração } \\
\text { das regras; } \\
\text { 2. Auxílio dos estudantes no } \\
\text { desenvolvimento de seu auto- } \\
\text { aperfeiçoamento e no auto- } \\
\text { monitoramento de suas habilidades. }\end{array}$ \\
\hline $\begin{array}{l}\text { RECONHECIMENTO }- \text { Razões } \\
\text { para o reconhecimento, distribuição } \\
\text { de recompensas e oportunidades para } \\
\text { as recompensas. }\end{array}$ & $\begin{array}{l}\text { 1. Reconhecimento do progresso } \\
\text { individual; } \\
\text { 2. Assegurar iguais oportunidades de } \\
\text { recompensas; } \\
\text { 3. Focar no auto-valor de cada criança. }\end{array}$ \\
\hline $\begin{array}{l}\text { RUPO - M } \\
\text { upo trabalha }\end{array}$ & $\begin{array}{l}\text { 1. Arranjos de grupos, flexíveis e } \\
\text { heterogêneos e múltiplos. }\end{array}$ \\
\hline
\end{tabular}




\begin{tabular}{|c|c|}
\hline $\begin{array}{l}\text { AVALIAÇÃO }- \text { Padrão para a } \\
\text { performance, monitoramento da } \\
\text { performance e feedback avaliativo. }\end{array}$ & $\begin{array}{l}\text { 1. Utilização de critérios de progresso } \\
\text { individuais; } \\
\text { 2. Envolvimento das crianças na auto- } \\
\text { avaliação; } \\
\text { 3. Fazer uma avaliação privada e } \\
\text { significativa. }\end{array}$ \\
\hline $\begin{array}{l}\text { TEMPO - Horário flexível, passos } \\
\text { para o aprendizado, administração do } \\
\text { trabalho de casa. }\end{array}$ & $\begin{array}{l}\text { 1. Prover oportunidade e tempo para a } \\
\text { melhora e progresso; } \\
\text { 2. Auxiliar às crianças no } \\
\text { estabelecimento de horários para a } \\
\text { prática e para o trabalho. }\end{array}$ \\
\hline
\end{tabular}

Figura 2 - Descrições do TARGET e estratégias de aula

Fonte: Ames (1992, citado por Valentini,2000, p. 22).

A análise do clima motivacional pode ser realizada através da filmagem das aulas dadas, obtendo resultados mais exatos para a caracterização do clima motivacional e, portanto, do tipo de orientação pedagógica.

\section{Metodologia}

Essa pesquisa é de natureza não experimental (Thomas e Nelson, 2002), carcterizando-se por uma pesquisa de natureza descritiva. Pariticparam do estudo vinte e três crianças entre quatro e cinco anos de idade. Os participantes foram divididos em dois grupos, de acordo com idade - grupo de quatro anos, com quatorze participantes e grupo de cinco anos, com nove participantes. A divisão ocorreu em função das crianças mais velhas já participarem dessa atividade extracurricular há mais tempo (três anos) quando comparadas com as crianças de quatro anos (dois anos).

Ambos os grupos receberam as mesmas aulas de ballet clássico em conjunto, cuja orientação pedagógica segundo análise do instrumento TARGET foi voltada para a tarefa. Todas as crianças são participantes do Curso Extracurricular de Ballet Clássico em uma escola de Educação Infantil da Rede Particular da cidade de Barueri $-\mathrm{SP}$. 
O pesquisador foi parte integrante da pesquisa, envolvendo-se na aplicação das aulas.

Os participantes tiveram duas (2) aulas de Ballet Clássico, por semana, durante doze (12) semanas, num total de vinte e quatro (24) aulas, com duração de cinqüenta minutos.

As aulas foram subdivididas em:

- Quinze (15) minutos de aquecimento

- Dez (10) minutos de alongamento

- Quinze (15) minutos de habilidades específicas do Ballet Clássico.

Uma avaliação diagnóstica foi realizada antes do início do programa. Os grupos foram submetidos a dois testes: um sobre a percepção de competência física e outro sobre o nível de execução de habilidades específicas do Ballet Clássico.

As mesmas avaliações foram realizadas ao final do programa.

\subsection{Estudo 1: percepção de competência}

O objetivo do estudo foi descrever a influência de uma intervenção pedagógica de Ballet Clássico, orientada para tarefa, na percepção de competência física.

\subsubsection{Sujeitos}

Vinte e três crianças entre quatro e cinco anos de idade, participantes de aulas de Ballet Clássico de uma escola particular de Educação Infantil.

\subsubsection{Instrumento}

Para avaliar o grau de competência física dos participantes, antes e após o programa, foi utilizado o instrumento: "Escala de Percepção de Competência e 
Aceitação Social para crianças" (The Pictorial Scale of Perceived Competence and Social Acceptence for Young Children - Harter and Pike, 1981) (APÊNDICE 1).

$\mathrm{O}$ instrumento de avaliação da percepção de competência utilizado no decorrer desse estudo foi desenvolvido por Susan Harter e Robin Pike, entre 1980 e 1983. Essa escala de avaliação da percepção de competência pode ser aplicada às crianças desde os quatro anos de idade até a adolescência. O intuito é verificar quão competentes, em todas as suas dimensões - física, cognitiva e social - eles se sentem.

Para a realização de testes que pudessem verificar a percepção de competência em crianças entre quatro e sete anos de idade, Susan Harter e Robin Pike procuraram acessar os julgamentos que as crianças têm delas mesmas separadamente, dentro de domínios específicos, como forma de traçar um perfil das próprias percepções através desses domínios. No entanto, somente seria possível construir um perfil da percepção de competência nos diferentes domínios, pressupondo-se que as crianças não vêem, elas mesmas, com igualdade em todos os domínios; melhor, elas são capazes de fazer distinções entre os diferentes domínios.

Portanto, a proposta de construção de uma Escala de Percepção de Competência para Crianças objetivou: (a) Criar um instrumento que pudesse ser sensível para a percepção de competência em domínios específicos; (b) Permitir a determinação de uma auto-estima global.

A escala foi construída, tendo como base, os domínios mais importantes na vida das crianças.

O formato é voltado para a escolha de uma das quatro alternativas apresentadas. Isso facilita a escolha e reduz a tendência da criança em dar respostas socialmente desejável. As situações apresentadas estão em forma de figuras, as quais descrevem habilidades e atividades específicas, minimizando, desta forma, os problemas com leitura e compreensão e ganhando o interesse das crianças pequenas.

$\mathrm{O}$ instrumento difere em alguns pontos de acordo com a idade, ou seja, algumas alternativas para as crianças entre 4 e 5 anos são diferentes quando 
comparadas às alternativas para as crianças entre 6 e 7 anos. Isso foi necessário pelo fato de que as habilidades específicas que definem ou conotam aceitação e competência social mudarem drasticamente por volta dos quatro anos. Por exemplo, o quebra-cabeça pode ser indicativo de competência cognitiva durante os anos préescolares, mas habilidades escolares orientadas - tais como: hábil para falar, ler ou adicionar - são medidas de competência cognitiva adequadas a primeiras e segundas séries do ensino fundamental.

Os conteúdos específicos das escalas descritos envolvem dois construtos gerais, percepção de competência e percepção de aceitação social. Existem duas subescalas dentro de cada um desses domínios. A percepção de competência é dividida em duas sub-escalas, competência cognitiva e competência física. A aceitação social é dividida em duas sub-escalas, aceitação dos outros e aceitação maternal. Existe, atualmente, uma nova versão do instrumento que utiliza mais três sub-escalas: aceitação paternal, aceitação do professor e conduta social.

Para este estudo, foi utilizada somente a sub-escala de Competência Física, ou seja, utilizaremos os seis itens para a avaliação da competência física somente.

\section{Itens para a avaliação da percepção de competência física}

Pré-escola/jardim

4 e 5 anos

\section{COMPETÊNCIA}

Primeira/Segunda Séries

$$
6 \text { e } 7 \text { anos }
$$
P 3
a) Bom em balançar
a) Bom em balançar *
H 7
b) Bom em escalar
b) Bom em escalar*
Y 11
c) Pode dar laços nos sapatos
c) Bom em quicar a bola
S $\quad 15$
d) Bom em saltitar
d) Bom em saltitar*
I 19
e) Bom em corrida
e) Bom em corrida* 


\section{A \\ $\mathrm{L}$}

Os itens em comum para ambas as idades apresentam o asterisco. As figuras acompanham cada uma das questões e apresentam as atividades sendo realizadas por meninos e meninas, separadamente, embora a atividade descrita seja a mesma. Isso se deve ao fato da aplicação do teste ser realizada individualmente, ou seja, para os meninos são apresentadas figuras com as atividades realizadas por meninos e para as meninas, figuras com atividades realizadas por meninas.

\subsubsection{Procedimentos de coleta de dados}

A coleta de dados teve a duração de dois dias. A aplicação do teste foi realizada com uma criança de cada vez e por uma única pessoa. Evitaram-se diferenças na maneira de aplicar e influência entre as crianças nas respostas.

A aplicação do teste seguiu os seguintes passos:

a) Apresentação para a criança de um item, através de duas figuras desenhadas em uma folha de papel - uma representando um menino/menina que salta bem e outra representando um menino/menina que não salta bem;

b) Após a apresentação, pede-se para ela apontar para a figura com a qual ela mais se parece (se com o(a) menino(a) que sabe pular bem ou com o(a) menino(a) que não sabe pular bem);

c) Depois que ela apontar a figura pergunta-se, mostrando os círculos (grande, para as respostas positivas e pequeno para as respostas negativas) desenhados na parte inferior de cada figura, se ela sempre consegue pular do jeito apontado ou se, somente às vezes, ela pula do jeito apontado;

d) De acordo com a resposta, a criança recebe uma pontuação - de 1 a 4 . Se a criança disser que sempre pula bem, recebe 4 pontos; se a criança responde que somente às 
vezes pula bem, recebe 3 pontos; se a criança responder que sempre não pula bem, recebe 1 ponto; e se a criança responder que muitas vezes não pula bem, recebe 2 pontos.

O número do valor correspondente para a escolha da criança foi registrado numa folha de pontuação individual de respostas. Nenhum comentário foi registrado no espaço da folha.

Após anotar o ponto referente à primeira figura, o avaliador segue para o próximo item, realizando a aplicação da mesma forma.

\subsubsection{Procedimentos de análise dos dados}

O formulário para a pré-escola/jardim está no APÊNDICE 2. Os itens estão na ordem apresentada para a criança. A escolha da criança é codificada na forma de uma pontuação de 1 a 4, registrado para a direita do número na própria coluna da subescala. A pontuação (1, 2, 3 ou 4) será registrada, baseada na escolha do círculo abaixo da figura

O protocolo de pontuação, simplesmente adiciona os seis números na coluna da sub-escala, colocando o total no Box apropriado abaixo de cada coluna. Então, divide-se esse total pelo número de itens da sub-escala - seis (a menos que, por alguma razão, algum item não tenha sido administrado, divide-se pelo atual número de itens validamente administrados). O valor numérico total da sub-escala alcançará de 6 (se a criança tiver se dado 1 para cada resposta) a 24 (se a criança se der 4 para cada resposta).

Para tratamento estatístico dos dados, foram utilizados os programas: Excel 2003, Minitab v.14 e Statistica v.7.

Por se tratarem de variáveis quantitativas em escala de razão (contínuas), foi testada, a priori, a normalidade da variável "competência física" por meio do teste $\mathrm{W}$ de Shapiro Wilk. Depois de verificada a normalidade da mesma foi realizado a comparação entre o "pré" e o "pós" teste desta variável (competência física) por meio 
do teste $t$ para amostras dependentes (teste $t$ pareado); teste este classificado como paramétrico. Foi adotado alfa $=0,05$ (nível de significância), sendo consideradas diferenças significativas aquelas cujo valor do nível descritivo $(p)$ fosse inferior a 0,05 .

\subsubsection{Resultados e Discussão}

Os resultados do estudo 1 mostraram que as crianças do grupo de quatro e de cinco anos de idade apresentaram uma percepção de competência física elevada, antes do início do programa ${ }^{1}$. Porém, ao final do programa ambos os grupos apresentaram uma percepção de competência física superior ao orimeiro teste (Figura $3)$.

1 É importante ressaltar que, segundo Susan Harter e Robin Pike (1981), a percepção de competência física que se apresenta maior que três é considerada alta, independentemente da margem de alteração. 


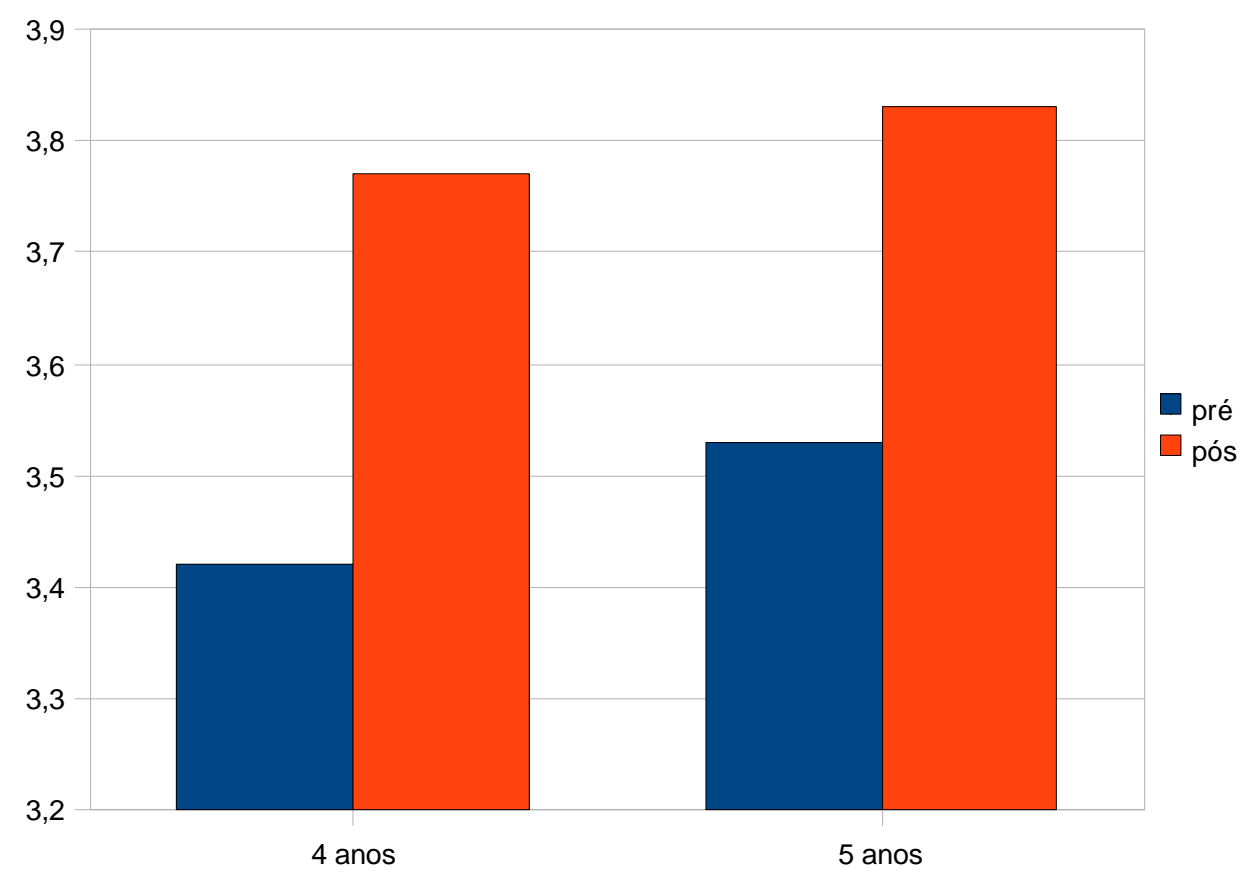

Figura 3 - Média de percepção de competência "pré" e "pós" programa

A média da percepção de competência física entre as crianças de quatro anos de idade foi de 3,42 ( $\mathrm{DP}=0,307182)$ antes do início do programa e de 3,77 ( $\mathrm{DP}=0,180421)$ após o programa. A média da percepção de competência física entre as crianças de cinco anos de idade foi de 3,53 ( $\mathrm{DP}=0,43186)$ antes do início do programa e de 3,83 ( $\mathrm{DP}=0,187846)$ após o programa.

Tabela 1 - Estatística das variáveis "competência física" nos grupos de 4 e 5 anos.

\begin{tabular}{|c|c|c|c|}
\hline Variável & média & $\boldsymbol{d} \boldsymbol{p}$ & p-valor \\
\hline \multirow{2}{*}{ Competência Física (4 anos) } & 3,42 & 0,307 & \multirow{2}{*}{$<0,001^{*}$} \\
\cline { 2 - 3 } & 3,77 & 0,180 & \\
\hline \multirow{2}{*}{ Competência Física (5 anos) } & 3,53 & 0,431 & \multirow{2}{*}{$<0,001^{*}$} \\
\cline { 2 - 3 } & 3,83 & 0,187 & \\
\hline
\end{tabular}

* estatisticamente significante. 
Conforme observado na tabela acima, houve uma diferença estatística entre o "pré" e o "pós" teste de acordo com o $p$-valor.

Embora o teste anterior ao programa já apresentasse uma percepção de competência elevada, os resultados sugerem que a intervenção pedagógica voltada para a tarefa mostra-se como um método eficiente para se ensinar Ballet Clássico para crianças entre quatro (4) e cinco (5) anos de idade. Os resultados apresentados encontram-se em acordo com os estudos Reinboth et al. (2006), Biddle et al. (2003), Yoo (1999), Biddle et al. (1999), para outras habilidades motoras.

Entretanto, recomenda-se a realização de mais estudos, mediante diferentes delineamentos, visando investigar o efeito de variáveis, tais como: idade, tipo de intervenção (maestria e desempenho), nível de desenvolvimento e tipo de habilidade.

\subsection{Estudo 2: Habilidades específicas do Ballet Clássico}

Esse estudo buscou verificar o nível execução de habilidades específicas do Ballet Clássico, antes e depois do programa.

\subsubsection{Sujeitos}

Vinte e três crianças, sendo treze crianças de quatro anos e nove crianças de cinco anos de idade, participantes de aulas de Ballet Clássico, de uma escola particular, de Educação Infantil.

\subsubsection{Instrumento}

Para avaliar o nível da execução das habilidades específicas do Ballet Clássico, antes e após o programa, foi construído um instrumento de avaliação para as crianças do grupo de quatro anos (sauté, tandue, demi-plié e chassé) e para as crianças do grupo de cinco anos (rélévé, port des brás, pás de chat, changesment em quinta posição). 
O instrumento foi analisado por cinco especialistas (professores, bailarinos e mestre em Ballet Clássico) que emitiram parecer favorável quanto à adequação das habilidades específicas do ballet para a idade, bem como em relação aos níveis de execução propostos para a avaliação do desempenho. Para cada habilidade específica do Ballet, o teste propõe três níveis de execução: básico, intermediário e avançado.

\section{Classificação das habilidades específicas do Ballet Clássico para as crianças do nível intermediário (5 anos)}

\begin{tabular}{|c|c|c|c|}
\hline Habilidade & básico & intermediário & avançado \\
\hline Relevé & $\begin{array}{l}\text { Faz demi-plié e não } \\
\text { consegue esticar os } \\
\text { joelhos ao subir na } \\
\text { meia ponta,perde o } \\
\text { equilíbrio na descida }\end{array}$ & $\begin{array}{l}\text { Faz demi-plié, estica } \\
\text { os joelhos na meia } \\
\text { ponta e desce sem } \\
\text { perder o equilíbrio }\end{array}$ & $\begin{array}{l}\text { Faz demi-plié, } \\
\text { esticas os joelhos } \\
\text { na meia ponta, } \\
\text { desce sem perder o } \\
\text { equilíbrio, faz plié } \\
\text { e estica as pernas } \\
\text { com os pés no } \\
\text { chão. }\end{array}$ \\
\hline $\begin{array}{l}\text { Port des brás, } \\
\text { em primeira } \\
\text { posição }\end{array}$ & 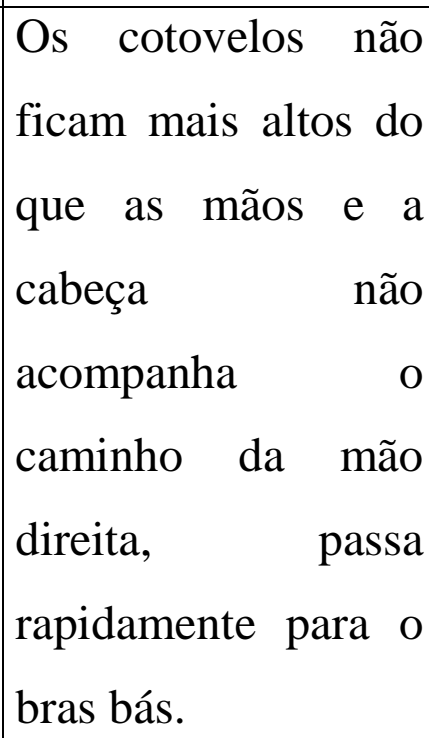 & 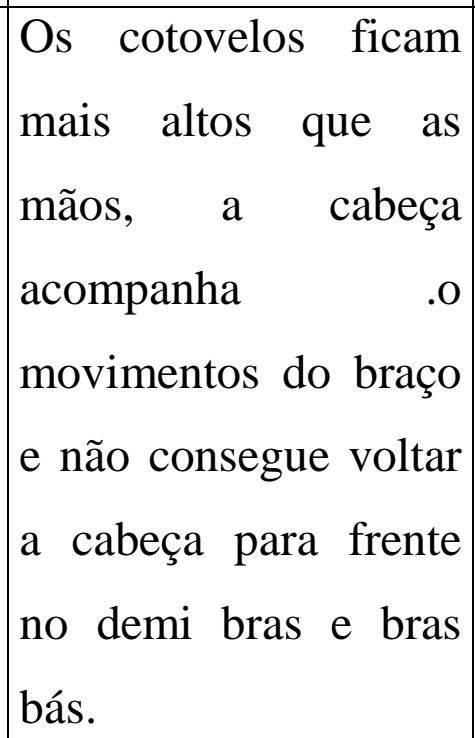 & $\begin{array}{l}\text { Os cotovelos } \\
\text { ficam mais altos } \\
\text { que as mãos, } \\
\text { cabeça acompanha } \\
\text { o movimento do } \\
\text { braço, consegue } \\
\text { voltar olhar na } \\
\text { realização do demi } \\
\text { bras e bras bás.. }\end{array}$ \\
\hline Pás de chat & Não consegue saltar & Consegue saltar com & Consegue \\
\hline
\end{tabular}




\begin{tabular}{|l|l|l|l|l|}
\hline & $\begin{array}{l}\text { com uma perna de } \\
\text { cada vez }\end{array}$ & $\begin{array}{l}\text { uma perna de cada } \\
\text { vez, mas não mantém } \\
\text { as duas no ar }\end{array}$ & $\begin{array}{l}\text { com uma perna de } \\
\text { cada vez e mantê- } \\
\text { las, ao mesmo } \\
\text { tempo, no ar. }\end{array}$ \\
\hline $\begin{array}{l}\text { Changesment } \\
3^{\mathrm{a}} \text { e } \quad 5^{\mathrm{a}} \\
\text { posições }\end{array}$ & $\begin{array}{l}\text { Somente alterna as } \\
\text { pernas para frente e } \\
\text { para trás, com os pés } \\
\text { paralelos. }\end{array}$ & $\begin{array}{l}\text { Alterna as pernas } \\
\text { cruzando-as frente e e } \\
\text { trás, sem se preocupar } \\
\text { com os pés em dehors. }\end{array}$ & $\begin{array}{l}\text { Alterna as pernas } \\
\text { cruzando-as frente } \\
\text { e trás, com os pés } \\
\text { em dehors. }\end{array}$ \\
\hline
\end{tabular}

Classificação das habilidades específicas do Ballet Clássico para as crianças do nível iniciante (4 anos)

\begin{tabular}{|c|c|c|c|}
\hline Habilidade & Básico & Intermediário & Avançado \\
\hline Saute & $\begin{array}{l}\text { Faz plié, pula, não } \\
\text { consegue esticar } \\
\text { as duas pernas no } \\
\text { ar e desce em plié }\end{array}$ & $\begin{array}{l}\text { Plié, pula } \\
\text { esticando as penas } \\
\text { no ar e desce em } \\
\text { plié }\end{array}$ & $\begin{array}{l}\text { Plié, pula esticando } \\
\text { as duas pernas no } \\
\text { ar, desce em plié, } \\
\text { sem perder o } \\
\text { equilíbrio. }\end{array}$ \\
\hline Tandue & $\begin{array}{l}\text { Coloca a ponta do } \\
\text { pé no chão com o } \\
\text { joelho } \\
\text { semiflexionado }\end{array}$ & $\begin{array}{l}\text { Coloca a ponta do } \\
\text { pé no chão com os } \\
\text { joelhos estendidos }\end{array}$ & $\begin{array}{l}\text { Arrasta o pé com os } \\
\text { joelhos estendidos }\end{array}$ \\
\hline Demi plié & $\begin{array}{l}\text { Flexiona as pernas } \\
\text { com o corpo um } \\
\text { pouco inclinado e } \\
\text { volta para a } \\
\text { posição inicial }\end{array}$ & $\begin{array}{l}\text { Flexiona as pernas } \\
\text { sem quase inclinar } \\
\text { o corpo, volta para } \\
\text { a posição inicial } \\
\text { com certo }\end{array}$ & $\begin{array}{l}\text { Flexiona as pernas, } \\
\text { sem inclinar o } \\
\text { corpo, volta para a } \\
\text { posição inical sem } \\
\text { desequilíbrio. }\end{array}$ \\
\hline
\end{tabular}




\begin{tabular}{|l|l|l|l|}
\hline & com desequilíbrio & desequilíbrio & \\
\hline Chassé & $\begin{array}{l}\text { Faz um passo para } \\
\text { o lado, sem }\end{array}$ & $\begin{array}{l}\text { Arrasta o pé de } \\
\text { saída e não pé de } \\
\text { arrastar o pé. }\end{array}$ & Arrasta os dois pés. \\
chegada. & \\
\hline
\end{tabular}

Para verificar a confiabilidade inter-avaliador das habilidades: 1 (Saute), 2 (Tandue), 3 (Demi plié) e 4 (Chassé) para o grupo de 4 anos e as habilidades: 1(rélévé), 2 (port dês brás), 3 (pás de chat) e 4 (changesment) para o grupo de 5 anos, foi realizado o teste Kappa ponderado, uma vez verificada a característica qualitativa ordinal das variáveis em questão.

Essa avaliação foi realizada por duas avaliadoras que não participaram do processo de elaboração do teste e pela pesquisadora, demonstrando um total de três avaliadoras. Cada uma das avaliadores analisaram a execução dos passos de duas crianças do grupo de quatro anos e duas crianças do grupo de cinco anos. Importante salientar que todas as avaliadoras analisaram as mesmas crianças.

Os resultados do teste como: o percentual de concordância entre os avaliadores, o intervalo de confiança baseado em $95 \%$ (intervalo de $95 \%$ em torno do percentual de concordância), o índice do Kappa ponderado, o erro padrão de kp, o Z que serve de base para o teste realizar a estatística e o nível de significância, se encontram na tabela a seguir:

Tabela 2- Estatística das variáveis "habilidades" nos grupos de 4 e 5 anos.

\begin{tabular}{|c|c|c|c|c|c|c|c|}
\hline Idade & Habilidade & $\begin{array}{c}\text { Percentual } \\
(\%)\end{array}$ & IC 95\% & $\begin{array}{c}\text { Kappa } \\
\text { pond. }\end{array}$ & e.p. & $\mathrm{Z}$ & p-valor \\
\hline 4 anos & 1 & 100,00 & $\begin{array}{c}80,74- \\
100,00\end{array}$ & 1,00 & 0,154 & 6,48 & $<0,001^{*}$ \\
\hline 4 anos & 2 & 92,86 & $\begin{array}{c}66,13- \\
99,82\end{array}$ & 0,86 & 0,149 & 5,63 & $<0,001^{*}$ \\
\hline 4 anos & 3 & 92,86 & $\begin{array}{c}66,13- \\
99,82\end{array}$ & 0,89 & 0,126 & 7,10 & $<0,001^{*}$ \\
\hline 4 anos & 4 & 100,00 & $\begin{array}{c}80,74- \\
100,00\end{array}$ & 1,00 & 0,121 & 8,21 & $<0,001^{*}$ \\
\hline 5 anos & 1 & 88,89 & $51,75-$ & 0,80 & 0,192 & 4,19 & $0,007^{*}$ \\
\hline
\end{tabular}




\begin{tabular}{|c|c|c|c|c|c|c|c|}
\hline & & & 99,72 & & & & \\
\hline 5 anos & 2 & 88,89 & $\begin{array}{c}51,75- \\
99,72\end{array}$ & 0,80 & 0,192 & 4,19 & $<0,001 *$ \\
\hline 5 anos & 3 & 100,00 & $\begin{array}{c}71,69- \\
100,00\end{array}$ & 1,00 & 0,183 & 5,21 & $<0,001 *$ \\
\hline 5 anos & 4 & 77,78 & $\begin{array}{c}39,99- \\
97,19 \\
\end{array}$ & 0,50 & 0,192 & 2,64 & $0,004^{*}$ \\
\hline
\end{tabular}

- resultado estatisticamente significativo

De acordo com a classificação de Landis \& Koch (1977), os valores maiores que 0,75 representam excelente concordância. Valores abaixo de 0,40 representam baixa concordância e valores situados entre 0,40 e 0,75 representam concordância mediana. Assim, conforme verificado na tabela supra-exposta e na clasificação de Landis \& Koch (1977), conclui-se que os três avaliadores apresentaram excelente concordância entre si ao realizarem o teste.

\subsubsection{Procedimento de coleta de dados}

As crianças foram avaliadas individualmente, para que não ocorresse interferência na execução dos passos.

Às crianças foi pedida a realização dos passos contidos na tabela, um de cada vez, e a avaliadora classificou a execução nos níveis pré-determinados (iniciante, intermediário ou avançado). O teste foi filmado para que a avaliadora pudesse classificar as crianças posteriormente.

\subsubsection{Procedimento de análise dos dados}

Quanto às variáveis qualitativas ordinais "habilidades específicas", foi realizada a comparação entre o "pré" e o "pós" teste por meio do teste nãoparamétrico para comparação de duas amostras dependentes (teste de Wilcoxon), adotando-se um $\alpha=0,05$.

Para cada criança foi elaborada uma tabela com o pré e o pós-teste. Cada um dos passos analisados recebeu nota, de acordo com o desempenho, ou seja, um (1) 
para nível básico, dois (2) para nível intermediário e três (3) para nível avançado. Ao final, realizava-se a somatória dos pontos, onde o mínimo a ser obtido era 4 e o máximo 12.

Exemplo:

\begin{tabular}{|c|c|c|}
\hline A & Pré-teste & Pós-teste \\
\hline Passo 1 & 1 & 3 \\
\hline Passo 2 & 1 & 3 \\
\hline Passo 3 & 1 & 3 \\
\hline Passo 4 & 1 & 3 \\
\hline Total & 4 & 12 \\
\hline
\end{tabular}

\subsubsection{Resultados e discussão}

Os resultados do estudo 2 - verificar o nível de a execução de habilidades específicas do Ballet Clássico, antes e depois do programa - mostraram que as crianças, tanto do grupo de quatro (4) anos quanto do grupo de cinco (5) anos melhoraram a execução das habilidades específicas do Ballet Clássico 


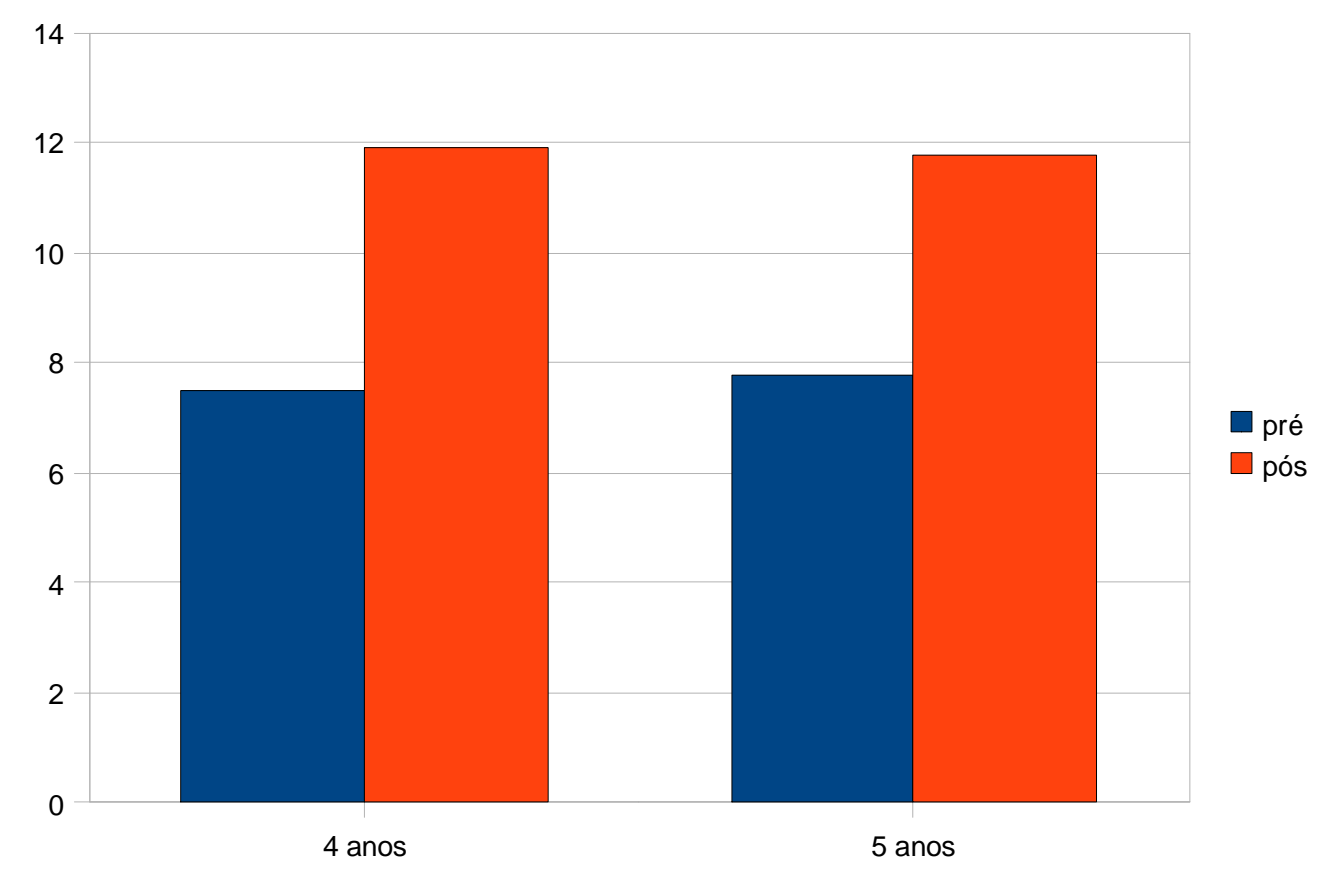

Figura 4 - Média da execução das habilidades específicas

A figura 4 mostra a evolução na execução da habilidades específicas, ou seja, antes do início do programa as crianças executaram as habilidades específicas numa média de 7,5 pontos ( $\mathrm{DP}=1,400549)$ para as crianças de quatro (4) anos e de 7,77 pontos $(\mathrm{DP}=0,666667)$ para as crianças de cinco (5) anos. Após o programa, a média na pontuação foi de 11,92 (DP=0,267261) para o grupo de quatro (4) anos e 11,77 $(\mathrm{DP}=0,440959)$ para o grupo de cinco (5) anos.

Tabela 3 - Estatística das variáveis "habilidades específicas" nos grupos de 4 e 5 anos de idade.

\begin{tabular}{|c|c|c|}
\hline Variável & $\mathbf{Z}$ & $\boldsymbol{p}$-valor \\
\hline Habilidade específica (4 anos) & 3,29 & $<0,001^{*}$ \\
\hline Habilidade específica (5 anos) & 2,66 & $0,007^{*}$ \\
\hline
\end{tabular}

* estatisticamente significante.

Conforme observado na tabela acima, houve uma diferença estatística entre o "pré" e o "pós" teste de acordo com o $p$-valor. 
A seguir apresentar-se-á a melhora no desempenho por habilidade separadamente (figuras 5 e 6 ).

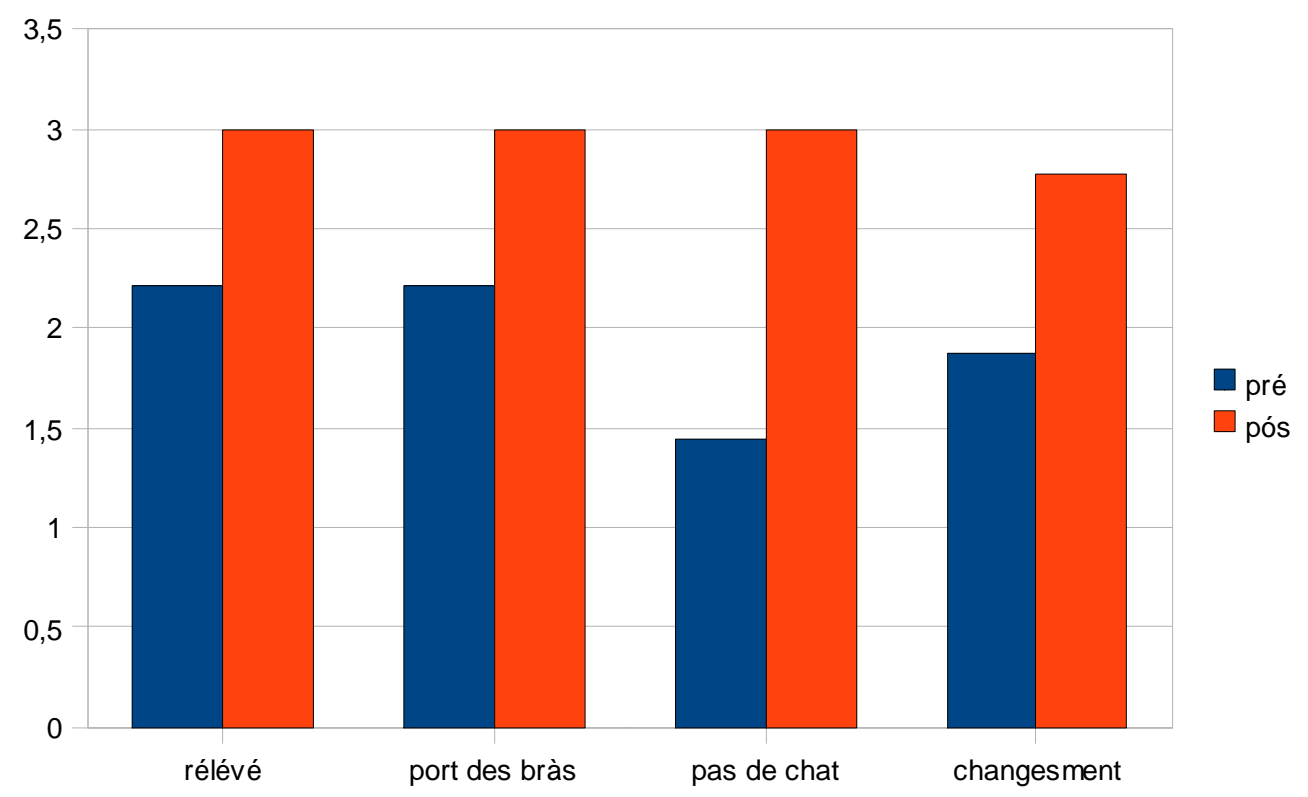

Figura 5 - Média de execução das habilidades específicas "pré" e "pós" programa para crianças de 5 anos

A figura 5 mostra a evolução, através da média na execução das habilidades específicas do Ballet Clássico por habilidade, para as crianças do grupo de cinco (5) anos. Todas as habilidades apresentaram melhora, merecendo uma atenção especial para o "pás de chat". Essa habilidade, no início do programa, foi a que teve o menor nível de execução, ou seja, grande parte das crianças conseguiu desenvolvê-la no nível básico. Em função disso, provavelmente, foi a habilidade que mais evoluiu.

A habilidade "rélévé" foi a habilidade com melhor execução no início do programa para todas as crianças e, no final, um nível avançado para todas as crianças. Interessante, também, foi o que aconteceu com a habilidade "changesment". Apresentou um nível entre básico e intermediário, no início do programa, mas não conseguiu apresentar-se no nível avançado, para todas as crianças, após o programa. A explicação para esse fato pode ser a complexidade do passo, que envolve salto, alternância de pernas e equilíbrio na finalização. 


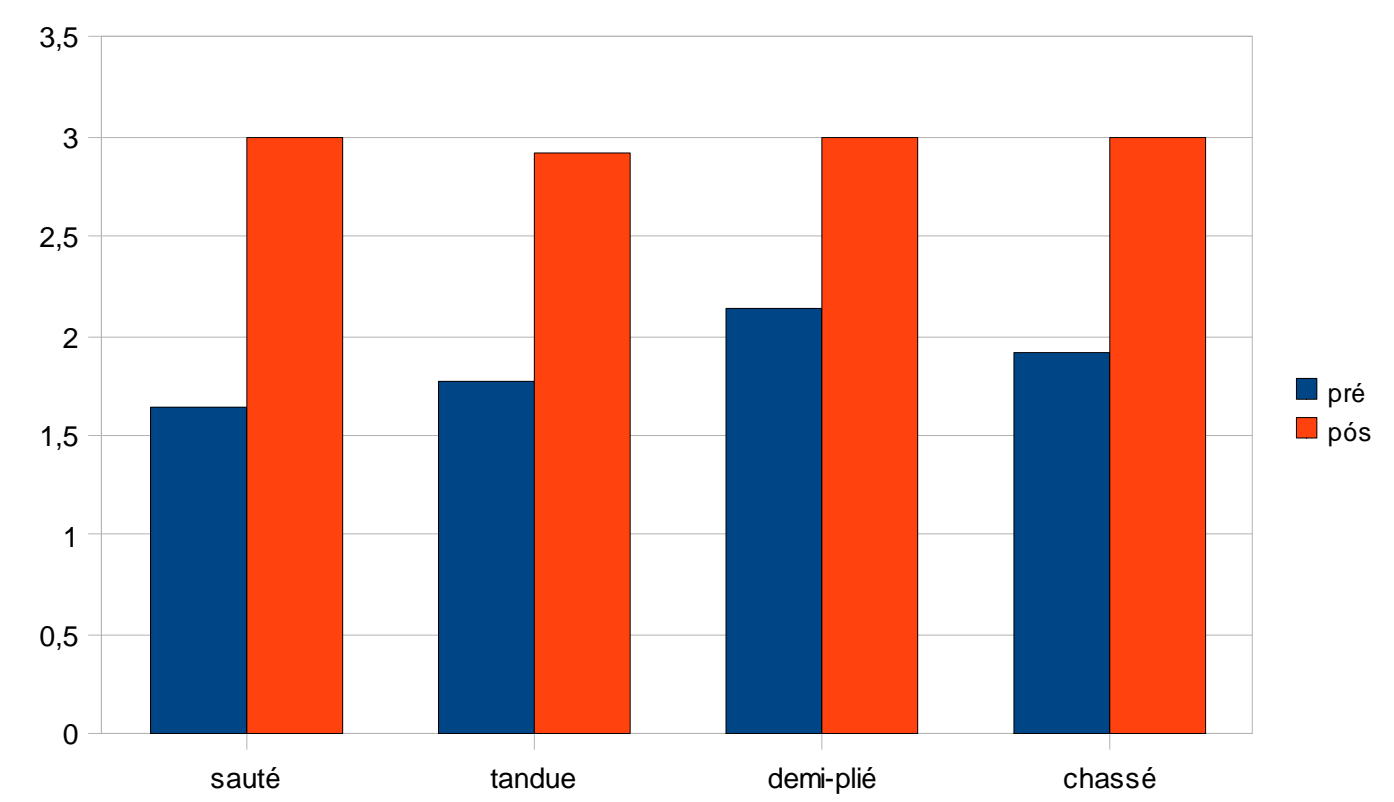

Figura 6 - Média da execução das habilidades específicas "pré" e "pós" programa para crianças de 4 anos

A figura 6 mostra a evolução, através da média, na execução das habilidades específicas do Ballet Clássico, por habilidade, para as crianças do grupo de quatro anos. Podemos observar que todas as habilidades apresentaram melhora, chegando próximo ao nível avançado. A habilidade que apresentou maior melhora foi o "sauté". No início do programa, mostrou-se como a habilidade de maior dificuldade para ser executada e, no entanto, no final do programa, apresentou-se no nível avançado. O "demi-plié", no início do programa, foi a habilidade que apresentou melhor execução e, portanto, após o programa, alcançou o nível avançado, na maioria das execuções.

Verificamos que todas as crianças de quatro anos executaram essas habilidades, alcançando o nível avançado, após o programa, exceção à habilidade "tandue".

Podemos observar que não foram as piores execuções antes do início do programaporém, foi a única habilidade que não conseguiu atingir o nível avançado para todas as execuções. Uma possível explicação pode estar no fato de sua execução exigir extremo controle de pernas, joelhos e pés, ou seja, para executar com precisão, as crianças necessitam arrastar os pés para "abrir" a perna sem flexionar os joelhos, e necessitam arrastar os pés sem flexionar os joelhos, para voltar à posição inicial. 
Com relação à execução das habilidades específicas do Ballet Clássico, verificamos que a maioria das crianças de quatro anos atingiram o nível avançado de execução (Figura 6). Esse resultado nos fez pensar na possibilidade de termos subestimado a capacidade das crianças. No entanto, essa dúvida foi minimizada quando observamos o nível de execução pré-programa. A grande maioria das crianças não apresentou um grau de execução avançado em, praticamente, nenhuma das habilidades, sugerindo que havia algo a ser aprendido.

A habilidade "sauté" foi a que apresentou maior evolução (100\% no nível avançado pós-programa - Figura 6) uma vez que no primeiro teste, comparado com as outras habilidades, o nível de execução foi muito próximo ao básico. Essa habilidade necessita de um controle postural bastante complexo - o impulso para o salto deve ser dado com mínima flexão das costas para frente - algo que requer concentração e equilíbrio. Desta forma, a maneira mais fácil de executá-lo é projetando as costas bem para frente, pois o impulso é maior (forma básica de execução do movimento). Ao aprender o movimento corretamente, a criança passa a perceber que com pequena flexão das costas para frente o equilíbrio para finalizar o movimento é maior e que o impulso para o salto é dado através da flexão dos joelhos, ou seja, a força está nas pernas.

A habilidade específica "tandue" apresentou uma execução próxima do nível intermediário (Figura 6) antes do início do programa. Isso se deve ao fato das crianças manterem os joelhos estendidos, no decorrer da execução, porém as pontas dos pés eram colocadas na lateral, ao invés de serem arrastadas. O nível avançado para essa habilidade consiste em arrastar o pé lateralmente, sem elevá-lo do chão, para o lado e arrastá-lo, novamente, para voltar à posição inicial. Arrastar o pé lateralmente para abrir a perna é um movimento que exige certa força e equilíbrio, uma vez que o centro de gravidade muda, ligeiramente, pois somente uma das pernas realizará o movimento. A consciência de que precisamos concentrar o peso do corpo em uma das pernas para não desequilibrar e conseguirmos realizar o movimento, necessita de um trabalho lento e muito lúdico, de conscientização dos centros de 
gravidade, das mudanças do corpo com os movimentos e das diferentes maneiras de locomoção.

No grupo de cinco anos, todas as crianças, em três habilidades específicas do Ballet Clássico, apresentaram o nível avançado de execução, no final do programa (Figura 5). Mediante esses resultados, pode-se inferir que um programa de Ballet Clássico com intervenção pedagógica voltada para a tarefa, em crianças de cinco anos de idade, promove aprendizagem das habilidades específicas propostas em um nível próximo ao avançado.

A habilidade que apresentou maior dificuldade de execução antes do programa foi o "pás de chat". Essa habilidade permite que o corpo se desloque, através de um salto lateral, com uma perna de cada vez, de um lado para outro. As crianças de cinco analisadas apresentaram dificuldade em deslocar o corpo para o lado esquerdo, por isso, muitas apresentaram o nível básico de execução, antes do início do programa. Outra dificuldade observada foi no deslocamento, saltando com uma perna de cada vez; a maioria das crianças saltava, com as duas pernas ao mesmo tempo, tanto para o lado direito quanto para o lado esquerdo. No final do programa, todas as crianças apresentaram o nível avançado na execução (Figura 5). Para isso, o trabalho realizado envolveu aspectos de lateralidade - lado direito/esquerdo e plano alto/baixo - e coordenação entre pernas.

A habilidade "changesment em $5^{\mathrm{a}}$ posição" não apresentou um nível avançado, para todas as crianças, no final do programa (Figura 5). O "changesment" é uma maneira mais complexa de realizar o "sauté". É um salto que envolve a troca dos pés, da frente para trás e vice-versa. Para que a execução seja perfeita, para crianças de cinco anos, elas precisam saltar e trocar os pés, antes de encostá-los no chão. Exige impulso com as pernas, sem flexionar, em excesso, as costas para frente e equilíbrio, em função da alternância do eixo gravitacional e da queda com os pés unidos. A troca dos pés mostra-se como a estrutura, do "changesment", mais difícil de ser executada, para as crianças. Pular uma corda estática no chão, para frente e para trás, com os dois pés, depois somente com um, depois cruzando as pernas é uma das tarefas mais 
agradáveis para as crianças, iniciando o processo de aprendizagem do movimento correto. Para pular a corda, as crianças precisam dar impulso com as pernas, pular de um pé só necessita de equilíbrio para não pisar na corda, cruzar os pés, primeiro um bem longe do outro para não pisar na corda e depois o mais próximo possível da corda. É um desafio emocionante e muito parecido com a execução do "changesment". Essa é uma das maneiras apresentadas, pelo programa, para a aprendizagem dessa habilidade. No entanto, por ser a habilidade mais complexa, acreditamos que as crianças precisariam de um tempo maior para aprendê-la, atingindo assim o nível avançado.

É importante ressaltar que não estamos objetivando, nesse trabalho, que as crianças atinjam o nível avançado de execução, para serem as melhores em comparação com outras crianças. Ao invés disso, focamos a evolução na aprendizagem da habilidade como maneira de garantir que as intervenções pedagógicas voltadas para a tarefa promovem o aprendizado tão consistente quanto outros tipos de intervenções pedagógicas o fazem, como por exemplo, as intervenções voltadas para o ego.

Todos os resultados apresentados estão de acordo com a literatura, no que diz respeito à aprendizagem por meio da intervenção pedagógica voltada para a tarefa.

No entanto, precisamos levar em consideração a limitação decorrente do número de sujeitos da amostra. Portanto, estudos com uma população mais abrangente são necessários, além de investigações que relacionem o tipo de intervenção pedagógica e o Ballet Clássico em diferentes tipos de instituições, para termos mais informações sobre a aprendizagem das habilidades específicas do Ballet.

Além disso, é importante ressaltar que as habilidades analisadas representam uma pequena parcela de passos do universo que compõe o Ballet Clássico. Porém, são as habilidades mais indicadas para serem ensinadas às crianças de quatro e cinco anos de idade, segundo os especialistas que analisaram o teste proposto.

\section{Conclusão}


A pesquisa objetivou descrever a influência da intervenção pedagógica voltada para a tarefa na percepção de competência física e na execução de habilidades específicas do Ballet Clássico, com crianças de quatro e cinco anos de idade.

Após a aplicação do programa, podemos concluir que as habilidades específicas analisadas apresentaram melhora na execução quando comparadas aos testes antes do início do programa.

Além disso, a percepção de competência física aumentou durante o programa. No entanto, não podemos garantir que esse aumento foi acarretado em função das aulas somente, uma vez que as atividades extra programa de dança não foram controladas

Sendo assim, estudos sobre diferentes tipos de intervenção pedagógica e Ballet Clássico, mediante delineamentos diversos, são necessários para se verificar a influência da intervenção pedagógica voltada à maestria na percepção de competência física e na aprendizagem de habilidades específicas próximas às exigências do Ballet tradicional.

O trabalho com ballet clássico infantil, mostra-se, em minha experiência pessoal, extremamente gratificante, principalmente por ter percebido, concretamente nessa pesquisa, que as crianças aprendem. Aprendem de maneira lúdica e adaptada às características físicas, sociais e emocionais da faixa etária, levando em consideração diferentes aspectos do processo de ensino-aprendizagem, tais como: interesse por diferentes tarefas, atividades anteriores pelas quais as crianças foram submetidas, no período de aula em sala e o quanto elas se apresentam dispostas para a aula.

Observar o envolvimento das crianças nas aulas, a adesão à atividade por anos durante a educação infantil, as apresentações de final de ano, onde todas, com muito entusiasmo dançam sem preocupação com pais e parentes na platéia e o resultado desta pesquisa, são aspectos importantes e motivadores para continuar pesquisando minha prática profissional. 


\section{Referências Bibliográficas}

1. Ames, C. Achievement attributions and self-instructions under competitive and individualistic goals structures. Journal of Educational Psychology, 76, 478-487, 1984.

2. Ames, C. Classroom: Goals, structures, and student motivation. Journal of Educational Psychology, 84, 409-414,1992

3. Ames, C.; Ames, R. Systems of student and teacher motivation: Toward a qualitative definition. Journal of Educational Psychology, 76, 535-556, 1984. (1984).

4. Ames, C.; Archer, J. Achievement of goal in the classroom: Student's learning strategies and motiation process. Journal of Educational Psychology, 80, 260-267, 1988.

5. Arribas, T. L.. A Educação Física de Três a Oito anos. São Paulo, Artmed, 2002.

6. Biddle, S. J. H.; Wang, C. K. J., ChatzisarantisN. L. D.; Spray, C. M. Motivaton for physical activity in young people: entity and incremental beliefs about athletic ability. Journal of Sports Sciences, 21, 973-989, 2003.

7. Biddle, S. J. H.; Soos I, Chatzisarantis; N. L. D.. Predicting physical activity inentions using a goal perspectives approach: a study of Hungarian younth. $\underline{\text { Scand }}$ Journal of Medicine \& Science in Sports, 9, 353-357, 1999.

8. Bois J. E.; Sarrazina P. G.; Brustadb R. J.;Trouillouda D. O.; François C. . Elementary schoolchildren's perceived competence and physical activity involvement: the influence of parents' role modeling behaviours and 
perceptions of their child's competence. Psychology of Sport and Exercise, 6, 381397, 2005.

9. Boucier, P.. História da dança no ocidente. São Paulo, Martins Fontes, 2006.

10. Brunel, P. C.. Relationship between achievement goal orientations and perceived motivational climate on intrinsic motivation. Scand Journal of Medicine \& Science in Sports, 9, 365-374, 1999.

11. Duda, J. L.. Motivation in Sport Settings: A goal perspective approach, in G. C. Roberts (ed.) Motivation in Sport and Exercise, 57-91. Champaign, IL: Human Kinetics, 1992.

12. Duda, J. L.. The relationship between mastery and competitive orientation and the perceived purpose of sport among male and female high school athletes. Journal of Sport and Exercise Psychology, 11, 318-335, 1989.

13. Duda, J. L.; Nicholls, J. G.. Dimensions of achievement motivation in schoolwork and sport. Journal of Educational Psychology , 84, 1-10,1992.

14. Duda, J. L.; Fox, K. R.;Biddle, S .J .H.; Armstrong, N.. Children's achievement goals and beliefs about success in sport. British Journal of Educational Psychology, 62, 313-323, 1992.

15. Duda, J. L.; Whitehead, J.. Measurement of goal perspectives in the physical domain. In Advances in Sportand Exercise Psychology Measurement (edited by J. L. Duda), 21-48. Morgantown, WV: Fitness InformationTechnology, 1998.

16. Dweck, C. S.. Motivational processes affecting learning. American Psychologist, 41, 1040-1048, 1986. 
17. Dweck, C. S.; Legget, E. L.. A social-cognitive approach to motivation and personality. Psychological Review, 95, 256-273, 1988.

18. Fox, K. R.,; Corbin, C.B.. The physical self-perception profile: Preliminary development and validation. Journal of Sport and Exercise Psychology, 11, 408-430, 1989.

19. Galahue, D.. Developmental Physical Education for today's elementary school children. Capítulo 5. New York, Macmilliam Publishing Company.

20. Goudas, M.; Biddle, S.; Fox, K..Perceived locus of causality, goal orientation, and perceived competence in school physical education classes. British Journal of Educational Psychology, 64, 453-463, 1994.

21. Hall, H.; Weinberg, R.; Jackson, A. (1987). Effects of goal specificity, goal difficulty, and information feedback on endurance performance. Journal os Sport Psychology, 9, 43-54.

22. Harter, S.. Effectance motivation reconsidered: Toward a developmental model. Human Development, 21, 34-64, 1978.

23. Harter, S.. A new self-report scale of intrinsic versus extrinsic orientaion in the classrom: Motivational and informational components. Developmental Psychology, 17, 300-312, 1981.

24. Harter, S.. The pictorial scale of perceived competence and social acceptance for young children. Child Development, 55, 1969-1982, 1984.

25. Harter, S.. Developmental Perspectives on the self-system.In. E. M. Hetherington 
(Ed.), Handbook of child psychology. (Vol.4): Socialization, personality and social development. Nova York: Wiley, 1983.

26. Harter, S.; Pike, R. G. The Pictorial Scale of Perceived Competence and Acceptance for Young Children - Plates (prescholl and kindergarten, male and female). Colorado Seminary. University of Denver.

27. Harter, S.; Pike, R. G. The Pictorial Scale of Perceived Competence and Acceptance for Young Children - Plates (first and seconde grades, male and female) Colorado Seminary. University of Denver.

28. Harter, S.; Pike, R. G.. The Pictorial Scale of Perceived Competence and Social Acceptance for Young Children - Procedural Manual. University of Denver.

29. Harter, S.. The Perceived Competence Scale for children. Child development, 53, 87-97, 1983.

30. Miller B. W.; Roberts G. C.; Ommundsen Y.. Effect of perceived motivational climate on moral functioning, team moral atmosphere perceptions, and the legitimacy of intentionally injurious acts among competitive youth football players. Psychology of Sport and Exercise, 6, 461-477, 2005.

31. Morgan, K.. Effects of manipulating the motivational climate in physical educations lessons. European Physical Education Review, 8 (3), 207-229, 2002.

32. Nicholls, J. G.. The competitive ethos and democratic education. Cambridge, MA: Harvard University Press.

33. Ommundsen, Y.; Roberts, G. C.; Kavussanu, M.. Perceived motivational climate 
and cognitive and affective correlates among Norwegian athletes. Journal of Sports Sciences, 16, 153-164, 1998.

29. Reinboth, M., Duda J. L. (2006). Perceived motivational climate, need satisfaction and indicesof well-being in team sports: A longitudinal perspective. Psychology of Sport and Exercise, 7, 269-286, 2006.

34. Ryan, R. M.; Frederick, C. M.. On energy, personality and health: subjective vitality as a dynamic reflection of wellbeing, Journal of Personality, 65, 529-565, 1997.

35. Sarrazin, P.; Bidlle, S.; Famose, J. P., Cury, F.; Fox K.; Durand, M.. Goal orientations and conceptions of the nature of sport ability in children: A social cognitive approach. British Journal Sociology and Psychology, 35, 399-414, 1996.

36. Thomas, R. J.; Nelson, J. K.. Método de pesquisa em atividade física, Artmed, 2002.

37. Trost, S. G.; Ward, D. S.; Moorehead, S. M., Watson, P. D.; Riner W.; Burke, J. R.. Validity of the computer science and applications (CSA) Activity Monitor in Children, Medicine and Science in Sports and Exercise, 30, 629-633, 1998.

38. Tzetzis, G.; Goudas, M.; Kourtessis, T. The relation of goal orientations to physical activity in physical education. European Physical Education Review, 8 (2), 177-188, 2002.

39. Valentini, N. C. (2000). The influence oh two motor skill interentions on the motor skill performance, perceived competence, and intrinsic motivation of kindergarten children. Dissertação de Mestrado. 
40. Vallerand, R. J.; Fortier, M. S.. Measures of intrinsic and extrinsic motivation in sport and physical activity: A review and critique. In Advances in Sportand Exercise Psychology Measurement (edited by J. L. Duda), 81-101. Morgantown, WV: Fitness InformationTechnology, 1998.

41. Yoo, J.. Motivational behavioral correlates of goal orientations and perceived motivational climate in physical education contexts. Perceptual And Motor Skills, 89, 262-274, 1999.

42. Weiss, M. R.; Bredemeier, B. J.; Schewchuk, R. M.. An intrinsic/extrinsic motivation scale for the youth sport stting: A confirmatory factor analysis. Journal of Sport Psychology, 7, 75-91, 1985.

43. Weiss, M. R.; Bredemeier, B. J.; Schewchuk, R. M.. The dynamics of perceived competence, perceived control, and motivational orientation in youth sport. In M. R. Weiss \& D. Gould (eds.), Sport for Children and Youths, 89-101, Champaign, IL: Human Kinetics.

44. White, S. A.; Kavussanu, M.; Tank K. M., Wingate; J.M. . Perceived parental beliefs about the causes of success in sport: relationship to athlets' achievement goals and personal beliefs. Scand Journal of Medicine \& Science in Sports, 14, 57-66, 2004.

45. White, R. Motivation reconsidered. The concept of competence. Psychology Review, 66, 297-323, 1959.

46. Whitehead, J. R.. A study os children's physical self-perceptions using an adapted physical self-perception profile questionnaire. Pediatric Exercise Science, 7, 132-151, 1995. 


\section{ANEXO I}

The pictorial scale of perceived competence and acceptance for young children 
ANEXO II

Registro individual e folha de pontuação 


\section{APÊNDICE 1}

Pontuação do teste de habilidades específicas para crianças de quatro anos

CRIANÇAS DE 4 ANOS - TESTE DE HABILIDADES ESPECÍFICAS

\begin{tabular}{|c|c|c|c|c|c|c|c|c|c|c|}
\hline Suj & \multicolumn{4}{|c|}{ Pré-teste } & total & \multicolumn{4}{|c|}{ Pós-teste } & total \\
\hline 1 & 1 & 2 & 2 & 2 & 7 & 3 & 3 & 3 & 3 & 12 \\
\hline 2 & 1 & 2 & 2 & 2 & 7 & 3 & 3 & 3 & 3 & 12 \\
\hline 3 & 2 & 2 & 2 & 3 & 9 & 3 & 3 & 3 & 3 & 12 \\
\hline 4 & 2 & 2 & 2 & 2 & 8 & 3 & 3 & 3 & 3 & 12 \\
\hline 5 & 2 & 2 & 2 & 2 & 8 & 3 & 3 & 3 & 3 & 12 \\
\hline 6 & 2 & 2 & 3 & 2 & 9 & 3 & 3 & 3 & 3 & 12 \\
\hline 7 & 1 & 2 & 1 & 1 & 5 & 3 & 3 & 3 & 3 & 12 \\
\hline 8 & 2 & 2 & 3 & 2 & 9 & 3 & 3 & 3 & 3 & 12 \\
\hline 9 & 2 & 1 & 2 & 2 & 7 & 3 & 3 & 3 & 3 & 12 \\
\hline 10 & 1 & 1 & 2 & 1 & 5 & 3 & 3 & 3 & 3 & 12 \\
\hline 11 & 2 & 2 & 2 & 2 & 8 & 3 & 3 & 3 & 3 & 12 \\
\hline
\end{tabular}




\begin{tabular}{|l|l|l|l|l|l|l|l|l|l|l|}
\hline 12 & 2 & 2 & 3 & 2 & 9 & 3 & 3 & 3 & 3 & 12 \\
\hline 13 & 2 & 2 & 2 & 2 & 8 & 3 & 3 & 3 & 3 & 12 \\
\hline 14 & 1 & 1 & 2 & 2 & 6 & 3 & 2 & 3 & 3 & 11 \\
\hline
\end{tabular}

APÊNDICE 2

Pontuação do teste de habilidades específicas para crianças de cinco anos 
CRIANÇAS DE 5 ANOS - TESTES DE HABILIDADES ESPECÍFICAS

\begin{tabular}{|c|c|c|c|c|c|c|c|c|c|c|}
\hline Suje & \multicolumn{4}{|c|}{ Pré-teste } & total & \multicolumn{4}{|c|}{ Pós-teste } & total \\
\hline 1 & 2 & 2 & 1 & 2 & 7 & 3 & 3 & 3 & 3 & 12 \\
\hline 2 & 2 & 2 & 2 & 2 & 8 & 3 & 3 & 3 & 3 & 12 \\
\hline 3 & 3 & 2 & 2 & 2 & 9 & 3 & 3 & 3 & 3 & 12 \\
\hline 4 & 2 & 3 & 1 & 1 & 7 & 3 & 3 & 3 & 2 & 11 \\
\hline 5 & 2 & 2 & 2 & 2 & 8 & 3 & 3 & 3 & 3 & 12 \\
\hline 6 & 2 & 3 & 1 & 2 & 8 & 3 & 3 & 3 & 3 & 12 \\
\hline 7 & 2 & 2 & 1 & 2 & 7 & 3 & 3 & 3 & 3 & 12 \\
\hline 8 & 3 & 2 & 1 & 2 & 8 & 3 & 3 & 3 & 3 & 12 \\
\hline 9 & 2 & 2 & 2 & 2 & 8 & 3 & 3 & 3 & 2 & 11 \\
\hline
\end{tabular}




\section{APÊNDICE 3}

Pontuação do teste de percepção de competência para crianças de quatro anos 
CRIANÇAS DE 4 ANOS - TESTE DE COMPETÊNCIA FÍSICA

\begin{tabular}{|c|c|c|}
\hline Suj & pré & pós \\
\hline 1 & 3,5 & 3,83 \\
\hline 2 & 3,3 & 3,66 \\
\hline 3 & 3,3 & 3,5 \\
\hline 4 & 3,16 & 3,66 \\
\hline 5 & 3,16 & 3,83 \\
\hline 6 & 3,66 & 3,83 \\
\hline 7 & 3,83 & 4 \\
\hline 8 & 3,83 & 3,83 \\
\hline 9 & 3,16 & 3,5 \\
\hline 10 & 3,16 & 4 \\
\hline 11 & 4 & 4 \\
\hline 12 & 3,33 & 3,83 \\
\hline 13 & 3,5 & 3,83 \\
\hline 14 & 3 & 3,5 \\
\hline total & 47,89 & 52,8 \\
\hline média & 3,420714 & 3,771429 \\
\hline Desvio padrão & 0,307182 & 0,180421 \\
\hline
\end{tabular}




\section{APÊNDICE 4}

Pontuação do teste de percepção de competência para crianças de cinco anos

CRIANÇAS DE 5 ANOS - TESTE DE COMPETÊNCIA FÍSICA

\begin{tabular}{|c|c|c|}
\hline Suj & pré & pos \\
\hline 1 & 3 & 3,5 \\
\hline 2 & 4 & 4 \\
\hline 3 & 4 & 4 \\
\hline 4 & 3,5 & 3,83 \\
\hline 5 & 3 & 3,66 \\
\hline 6 & 4 & 4 \\
\hline 7 & 3,83 & 4 \\
\hline 8 & 3,33 & 3,83 \\
\hline 9 & 3,16 & 3,66 \\
\hline
\end{tabular}




\begin{tabular}{|c|c|c|}
\hline total & 31,82 & 34,48 \\
\hline média & 3,535556 & 3,831111 \\
\hline Desvio padrão & 0,43186 & 0,187846 \\
\hline
\end{tabular}

APÊNDICE 5

Pontuação individual dos avaliadores na execução das habilidades específicas para o grupo de quatro anos e de cinco anos 
Crianças de quatro anos

Habilidade 1 - Saute

\begin{tabular}{|c|c|c|c|}
\hline sujeito & Avaliador 1 & Avaliador 2 & Avaliador 3 \\
\hline 1 & 1 & 1 & 1 \\
\hline 2 & 1 & 1 & 2 \\
\hline 3 & 2 & 2 & 2 \\
\hline 4 & 2 & 2 & 2 \\
\hline 5 & 2 & 2 & 2 \\
\hline 6 & 2 & 2 & 1 \\
\hline 7 & 1 & 1 & 2 \\
\hline 8 & 2 & 2 & 1 \\
\hline 9 & 2 & 2 & 2 \\
\hline 10 & 1 & 1 & 2 \\
\hline 11 & 2 & 2 & 1 \\
\hline 12 & 2 & 2 & 2 \\
\hline 13 & 2 & 1 & 2 \\
\hline 14 & 1 & & \\
\hline
\end{tabular}

Habilidade 2 - Tandue

\begin{tabular}{|c|c|c|c|}
\hline sujeito & Avaliador 1 & Avaliador 2 & Avaliador 3 \\
\hline 1 & 2 & 2 & 2 \\
\hline 2 & 2 & 2 & 2 \\
\hline 3 & 2 & 1 & 2 \\
\hline 4 & 2 & 2 & 2 \\
\hline 5 & 2 & 2 & 2 \\
\hline 6 & 2 & 2 & 2 \\
\hline 7 & 2 & 2 & 2 \\
\hline 8 & 2 & 2 & \\
\hline
\end{tabular}




\begin{tabular}{|c|c|c|c|}
\hline 9 & 1 & 1 & 1 \\
\hline 10 & 1 & 1 & 1 \\
\hline 11 & 2 & 2 & 2 \\
\hline 12 & 2 & 2 & 2 \\
\hline 13 & 2 & 2 & 2 \\
\hline 14 & 1 & 1 & 1 \\
\hline
\end{tabular}

Habilidade 3 - Demi plié

\begin{tabular}{|c|c|c|c|}
\hline sujeito & Avaliador 1 & Avaliador 2 & Avaliador 3 \\
\hline 1 & 2 & 2 & 2 \\
\hline 2 & 2 & 2 & 2 \\
\hline 3 & 2 & 2 & 2 \\
\hline 4 & 2 & 2 & 2 \\
\hline 5 & 2 & 2 & 3 \\
\hline 6 & 3 & 3 & 1 \\
\hline 7 & 1 & 1 & 3 \\
\hline 8 & 3 & 3 & 2 \\
\hline 9 & 2 & 2 & 2 \\
\hline 10 & 2 & 2 & 3 \\
\hline 11 & 2 & 2 & 2 \\
\hline 12 & 3 & 3 & 2 \\
\hline 13 & 2 & 2 & 2 \\
\hline 14 & 2 & & 2 \\
\hline
\end{tabular}

Habilidade 4 - Chassé

\begin{tabular}{|c|c|c|c|}
\hline sujeito & Avaliador 1 & Avaliador 2 & Avaliador 3 \\
\hline 1 & 2 & 2 & 2 \\
\hline 2 & 2 & 2 & 2 \\
\hline 3 & 3 & 3 & 2 \\
\hline 4 & 2 & 2 & 2 \\
\hline 5 & 2 & 2 & 2 \\
\hline 6 & 2 & 2 & 1 \\
\hline 7 & 1 & 1 & 2 \\
\hline 8 & 2 & 2 & 1 \\
\hline 9 & 2 & 2 & 2 \\
\hline 10 & 1 & 1 & 2 \\
\hline 11 & 2 & 2 & 2 \\
\hline 12 & 2 & 2 & 2 \\
\hline 13 & 2 & 2 & 2 \\
\hline 14 & 2 & & \\
\hline
\end{tabular}


Habilidade 1 - rélévé

\begin{tabular}{|c|c|c|c|}
\hline sujeito & Avaliador 1 & Avaliador 2 & Avaliador 3 \\
\hline 1 & 2 & 2 & 2 \\
\hline 2 & 2 & 2 & 2 \\
\hline 3 & 3 & 3 & 3 \\
\hline 4 & 2 & 2 & 2 \\
\hline 5 & 2 & 2 & 2 \\
\hline 6 & 2 & 2 & 3 \\
\hline 7 & 2 & 2 & 3 \\
\hline 8 & 3 & 3 & 2 \\
\hline 9 & 2 & 2 & \\
\hline
\end{tabular}

Habilidade 2 - port dês bràs

\begin{tabular}{|c|c|c|c|}
\hline sujeito & Avaliador 1 & Avaliador 2 & Avaliador 3 \\
\hline 1 & 2 & 3 & 2 \\
\hline 2 & 2 & 2 & 2 \\
\hline 3 & 2 & 2 & 3 \\
\hline 4 & 3 & 3 & 2 \\
\hline 5 & 2 & 2 & 3 \\
\hline 6 & 3 & 3 & 2 \\
\hline 7 & 2 & 2 & 2 \\
\hline 8 & 2 & 2 & 2 \\
\hline 9 & 2 & 2 & \\
\hline
\end{tabular}

Habilidade 3 - pás de chat

\begin{tabular}{|c|c|c|c|}
\hline sujeito & Avaliador 1 & Avaliador 2 & Avaliador 3 \\
\hline 1 & 1 & 1 & 2 \\
\hline 2 & 2 & 2 & 2 \\
\hline 3 & 2 & 2 & 1 \\
\hline 4 & 1 & 1 & 2 \\
\hline 5 & 2 & 2 & 1 \\
\hline 6 & 1 & 1 & 1 \\
\hline 7 & 1 & 1 & 1 \\
\hline 8 & 1 & 1 & 2 \\
\hline 9 & 2 & 2 & \\
\hline
\end{tabular}

Habilidade 4 - changesment

\begin{tabular}{|c|c|c|c|}
\hline sujeito & Avaliador 1 & Avaliador 2 & Avaliador 3 \\
\hline 1 & 2 & 2 & 1 \\
\hline 2 & 2 & 2 & 2 \\
\hline 3 & 2 & 2 & 1 \\
\hline 4 & 1 & 1 & 2 \\
\hline 5 & 2 & 2 & 2 \\
\hline 6 & 2 & 2 & \\
\hline
\end{tabular}




\begin{tabular}{|l|l|l|l|}
\hline 7 & 2 & 2 & 2 \\
\hline 8 & 2 & 2 & 2 \\
\hline 9 & 2 & 1 & 2 \\
\hline
\end{tabular}

